\title{
ESTIMATIVAS MENSAIS DA FORMAÇÃO BRUTA DE CAPITAL FIXO PÚBLICA NO BRASIL (2002-2010)
}

\author{
Claudio H. M. dos Santos ${ }^{*}$, Rodrigo O. Orair ${ }^{\dagger}$, Sergio W. Gobettio $^{\ddagger}$, \\ Alessandra S. Ferreira ${ }^{\S}$, Wanderson S. Rocha ${ }^{\mathbb{I}}$, Hilton L. da Silva ${ }^{\prime \prime}$ José \\ M. BRitTo \\ Resumo
}

Este artigo apresenta estimativas inéditas de séries mensais da formação bruta de capital fixo (FBCF) das administrações públicas no Brasil de 2002 a 2010. A estimação exigiu um esforço significativo de pesquisa. Em primeiro lugar, realizou-se uma análise criteriosa dos conceitos da contabilidade pública e da contabilidade nacional, enfatizando-se as peculiaridades do processo orçamentário brasileiro que enviesam as estimativas anuais dos investimentos públicos divulgadas nas estatísticas oficiais e que afetam a precisão das informações de alta frequência. Em segundo lugar, desenvolveram-se procedimentos para mitigar estes problemas. Por fim, buscou-se contornar a escassez de informações dos governos subnacionais solicitando-se informações adicionais de centenas de contadores públicos, técnicos ou secretários de Fazenda/Planejamento de todos os estados da Federação, do Distrito Federal (DF) e dos maiores municípios.

Palavras-chave: Investimento público; Formação bruta de capital fixo da administração pública; Séries temporais mensais.

\begin{abstract}
This article presents new monthly estimates of the gross fixed capital formation of the Brazilian general government for the 2002-2010 years. A significant research effort was made to carry out the estimations. First, the many differences between the concepts of "public investment" (as used in the Brazilian public accounting manuals) and "gross fixed capital formation of the general government" (as used in the United Nations System of National Accounts) were carefully identified, and so were the peculiarities of the Brazilian budget process that distort official estimates of the annual gross fixed capital formation of the Brazilian general government and affect the precision of naive estimates of the same variable in higher frequencies. Second, several procedures were developed to correct or mitigate these problems. Finally, additional information was obtained from 20 out of 26 Brazilian states, the federal district, and tens of (large) municipalities in order to allow us to circumvent the relative scarcity of information on the finances of Brazilian state and local governments.
\end{abstract}

Keywords: Public investment; Gross fixed capital formation of the public sector; Monthly time series.

JEL classification: C82, E01, H54, H76, H83

\footnotetext{
* IPEA. Email: claudio.santos@ipea.gov.br. ${ }^{\dagger}$ IPEA, email: rodrigo.orair@ipea.gov.br. ‡ IPEA, email: sergio.gobetti@ipea.gov.br. §IPEA, email: ale.alessandrasf@gmail.com. II IPEA, email: 7wanderson7@gmail.com. II IPEA. Email: hhlsilva@gmail.com. ${ }^{* *}$ IPEA, email: mauricio.britto@ipea.gov.br.
} 


\section{Introdução}

Desde que foram instituídas pelo Instituto Brasileiro de Geografia e Estatística (IBGE), as contas nacionais trimestrais têm sido intensivamente utilizadas pelos economistas em análises conjunturais. Entretanto, são relativamente poucas as tentativas na literatura de utilizá-las sistematicamente (e variáveis relacionadas) na construção de modelos de consistência macroeconômica de base trimestral para a economia brasileira. ${ }^{1}$ Tal lacuna reflete, em grande medida, as próprias limitações das contas nacionais trimestrais, sobretudo no âmbito da administração pública. Inexistem, em particular, dados oficiais de alta frequência para as cargas tributárias bruta e líquida da economia, para a poupança e as necessidades de financiamento da administração pública e para a desagregação da formação bruta de capital fixo (FBCF) total da economia em FBCF privada e FBCF da administração pública - variáveis cuja importância teórica e prática é reconhecida por virtualmente todas as escolas de pensamento em macroeconomia.

É verdade que a adoção do Novo Sistema de Contas Nacionais (NSCN) em 2007 (referência 2000), seguindo algumas das últimas recomendações dos organismos internacionais (IBGE 2008a), representou um notável avanço nas contas nacionais do Brasil. Para o objetivo específico deste trabalho, destacamse a atualização das formas de cálculo e melhor detalhamento da conta econômica integrada do setor institucional Administração Pública (APU) e o uso cada vez mais amplo dos relatórios da contabilidade pública como fonte primária de dados.

Note-se, no entanto, que os avanços estão, em grande medida, restritos às contas nacionais anuais - que são publicadas com certa defasagem — e ainda não há estimação das contas econômicas integradas por setores institucionais nas contas nacionais trimestrais. Além disso, em 2006 o IBGE deixou de publicar a pesquisa Finanças Públicas do Brasil que apresentava informações detalhadas sobre as administrações públicas nos três níveis de governo. Embora vários dados da pesquisa sejam disponibilizados nas contas nacionais anuais, muito se perdeu com o seu cancelamento - em particular, a desagregação dos dados da APU por nível de governo.

O presente trabalho visa contribuir para o preenchimento de algumas das lacunas supracitadas apresentando estimativas mensais inéditas para a FBCF da APU no período 2002-2010, desagregadas por nível de governo. Nesse sentido, dá-se aqui prosseguimento a esforços similares de construção de séries fiscais de alta frequência baseadas na metodologia das contas nacionais (por exemplo, dos Santos \& Costa 2008, dos Santos et al. 2010, Gobetti \& Orair 2010, Orair et al. 2011).

Note-se que a construção das séries de alta frequência da FBCF da APU exigiu um significativo esforço de pesquisa. Em primeiro lugar, realizou-se uma análise criteriosa dos conceitos da contabilidade pública e da contabilidade nacional, enfatizando-se, em particular, as peculiaridades do processo orçamentário brasileiro que enviesam as estimativas anuais dos investimentos públicos divulgadas nas estatísticas oficiais da Secretaria do Tesouro Nacional (STN) e do IBGE (Gobetti 2007) e que afetam particularmente a precisão das informações de alta frequência. Em segundo lugar, desenvolveram-se proce-

\footnotetext{
${ }^{1}$ Cavalcanti (2000) e Muinhos \& Alves (2003) são duas (e incompletas e/ou preliminares) exceções que confirmam esta regra.
} 
dimentos para mitigar os referidos problemas, a fim de viabilizar a construção de séries mais precisas da FBCF da APU. Em terceiro lugar, buscou-se contornar a escassez de informações dos governos subnacionais, solicitandose informações adicionais de contadores públicos, técnicos ou secretários de Fazenda/Planejamento de todos os estados da Federação, do DF e de 160 municípios - muitos dos quais gentilmente se dispuseram a enviar dados para este trabalho (ver o Apêndice B).

O restante do trabalho está dividido em três seções. A segunda seção, a seguir, revisita conceitos de contas nacionais e contabilidade pública e aborda as peculiaridades do processo orçamentário, com destaque para o viés presente nas estatísticas oficiais de investimentos públicos. Na sequência, discutem-se os critérios alternativos de mensuração da FBCF da APU que eliminam este viés e seus eventuais impactos sobre a FBCF total da economia. A terceira seção, por sua vez, discute os procedimentos e bases de dados utilizados na construção das estimativas mensais da FBCF da APU. Também são apresentados brevemente os principais resultados. Por fim, notas à guisa de conclusão são apresentadas na quarta e última seção do trabalho. As estimativas propriamente ditas são apresentadas no Apêndice C.

\section{Os passos do argumento: conceitos básicos de contabilidade pública e contabilidade nacional, sua não trivial compatibilização e as peculiaridades do processo orçamentário brasileiro}

\subsection{Investimentos da Contabilidade Pública versus FBCF}

Os relatórios da contabilidade pública brasileira são as fontes primárias no cálculo da conta econômica integrada do setor institucional APU das contas nacionais, complementados por pesquisas próprias do IBGE. É possível identificar alguns avanços recentes que facilitam o cálculo da FBCF da APU a partir das informações dos relatórios da STN, como a padronização dos demonstrativos contábeis dos governos subnacionais e a divulgação de uma série histórica com informações consolidadas das três esferas de governo desde $2000 .^{2}$ Contudo, a tradução da contabilidade pública para a contabilidade nacional não é imediata e sua compatibilização exige o esclarecimento prévio de alguns conceitos.

A classificação das despesas públicas se faz de acordo com a "natureza da despesa orçamentária" que corresponde aos cinco níveis ilustrados na Figura

\footnotetext{
${ }^{2}$ Entre as fontes de dados primárias citadas nos relatórios metodológicos do IBGE (2008a) estão as informações da contabilidade pública - o Balanço Geral da União, o Sistema Integrado de Administração Financeira (Siafi) da STN para o governo federal (GF); a Execução Orçamentária dos Estados (EOE); Finanças do Brasil (Finbra) da STN para os municípios — mas também levantamentos contábeis especiais e pesquisas próprias como as "Pesquisas Estatísticas Econômicas das Administrações Públicas" da Coordenação de Contas Nacionais (CONAC)/IBGE para os governos estaduais e municípios das capitais e regiões metropolitanas. Em grande medida, a opção do IBGE por utilizar mais amplamente os relatórios fiscais pode ser atribuída às melhorias qualitativas nestes relatórios, principalmente após a "Lei de Responsabilidade Fiscal" (LRF) de maio de 2000, que determinou a uniformização dos procedimentos de execução orçamentária e atribuiu ao órgão central da contabilidade da União — a STN do Ministério da Fazenda (MF) — a função de consolidação, nacional e por esfera de governo, das contas públicas. Incluindo-se a Portaria Interministerial STN/Secretaria do Orçamento Federal (SOF) n. 163, de 4 de maio de 2001, que atualizou os conceitos e estendeu a classificação da "natureza de despesa", antes restrita ao nível federal, para estados e municípios.
} 
1. O primeiro nível de classificação, a categoria econômica, é o mais genérico e de pouco proveito para os propósitos deste estudo; discriminando-se entre despesa de capital, que contribui para a formação ou aquisição de um bem de capital (não necessariamente FBCF), e a despesa corrente que não contribui. É no segundo nível de classificação que as despesas são desdobradas em grupos mais específicos, os chamados grupos de natureza de despesa: 1) Pessoal e encargos sociais; 2) Juros e encargos da dívida; 3) Outras despesas correntes; 4) Investimentos; 5) Inversões financeiras; 6) Amortização de dívidas; e 7) Reserva de contingência.

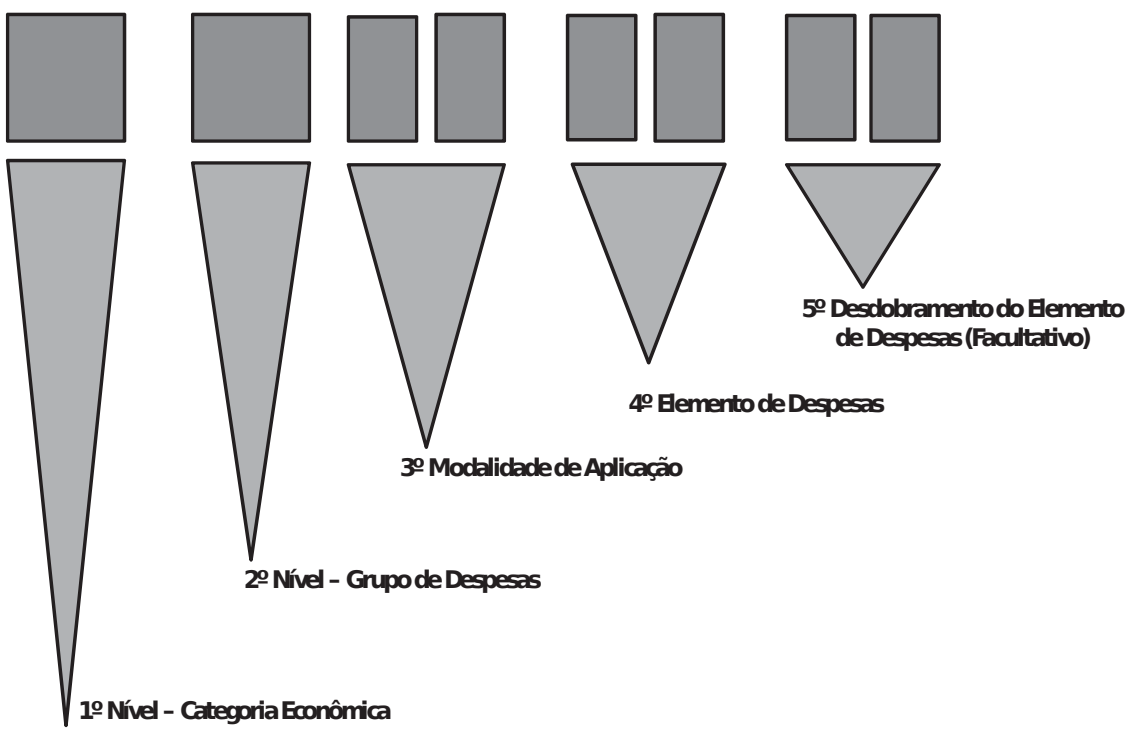

Figura 1: Classificação da Natureza da Despesas Orçamentária

A ênfase deste trabalho recai especificamente sobre o grupo de despesa de investimentos (ou GND4 no jargão orçamentário) da contabilidade pública. Ressalte-se que o conceito de despesa de investimento da contabilidade pública é distinto do (ainda que similar ao) conceito de FBCF das contas nacionais, como se pode concluir a partir da Tabela 1. A compatibilização desses conceitos envolve uma série de considerações.

Começa-se por observar que a informação sobre a "modalidade de aplicação" - o terceiro nível de classificação apresentado na Figura 1 - deve ser utilizada complementarmente para fins de consolidação das contas públicas e cálculo da FBCF da APU. A modalidade de aplicação indica se os recursos são aplicados pela própria esfera de governo, demais entes da Federação ou até mesmo por entidades privadas ou no exterior, entre outros possíveis recebedores finais de recurso. Esta informação é fundamental porque identifica a esfera de governo responsável pela execução do investimento.

A Tabela 2 mostra os montantes dos investimentos por modalidades de despesa e permite esclarecer estes argumentos. Para fins de cálculo da FBCF da APU, devem-se agregar as despesas de "investimentos" na modalidade "aplicações diretas" por cada ente federado, isto é, o valor de cerca de R\$ 82,7 
Tabela 1: Conceitos de Investimentos da Contabilidade Pública e de FBCF da Contabilidade Nacional.

\section{Despesas de Investimentos da Contabilidade Pública}

Lei de Finanças Públicas que regulamenta o processo orçamentário brasileiro, Lei 4.320 de 17 de março de 1964

Portaria Interministerial $\mathrm{n}^{\circ} 163$ de 4 de maio de 2001 que uniformiza procedimentos e dispõe sobre normas gerais de consolidação das contas públicas. STN/SOF (2001)
(...) classificam-se como investimentos as dotações para o planejamento e a execução de obras, inclusive as destinadas à aquisição de imóveis considerados necessários à realização destas últimas, bem como para os programas especiais de trabalho, aquisição de instalações, equipamentos e material permanente e constituição ou aumento do capital de empresas que não sejam de caráter comercial ou financeiro.

Despesas orçamentárias com softwares e com o planejamento e a execução de obras, inclusive com a aquisição de imóveis considerados necessários à realização destas últimas, e com a aquisição de instalações, equipamentos e material permanente.

FBCF da contabilidade nacional

SCN (1993) da Organização das Nações Unidas

Relatório metodológico do IBGE (2008a, pp.35-36)
A FBCF de um determinado setor institucional é "medida pelo valor total (...) da aquisição, menos o valor total das vendas, de ativos fixos [pelo referido setor institucional] durante o período contábil, mais certas adições ao valor dos produtos não produzidos feitas por meio da atividade produtiva (...). Ativos fixos são ativos tangíveis ou intangíveis resultantes de processos de produção e que são utilizados repetida e continuamente em outros processos de produção por mais de um ano" (tradução e grifo dos autores).

A FBCF "inclui o valor da aquisição de bens de capital novos, da importação de bens de capital usados e as aquisições, líquidas de cessões, de bens de capital já existentes na economia nacional. Quanto às categorias de ativos considerados, destacam-se os bens imóveis (construções residenciais, comerciais, industriais, obras de infraestrutura, etc.) e móveis (meios de transporte, máquinas, equipamentos e outros bens de capital). A formação bruta de capital fixo inclui, ainda, o valor dos serviços ligados à instalação dos bens de capital, dos bens e serviços incorporados aos terrenos, das melhorias que elevam a vida útil dos ativos existentes, assim como o valor dos gastos inerentes à transmissão de propriedades de terrenos, edifícios e outros bens de capital existentes. Ficam excluídos da formação bruta de capital fixo o valor da aquisição de pequenos equipamentos, como as máquinas-ferramentas, o gasto com manutenções e reparações ordinárias em ativos tangíveis, bens de consumo duráveis adquiridos pelas famílias e despesas com pesquisas e desenvolvimento"

Fonte: Elaboração Própria. 
bilhões apresentado na última coluna da Tabela 2. O total de "investimentos" de R\$108,3 bilhões inclui a contabilização indevida de uma parcela de transferências de capital a entidades que não fazem parte da administração pública e, principalmente, a dupla contagem dos recursos transferidos ou descentralizados para outras esferas de governo. A informação de modalidade de aplicação nem sempre está disponível nos relatórios contábeis e sua ausência leva a uma superestimação do investimento público. ${ }^{3}$

Tabela 2: Despesas de investimento do GF, governo estadual (GE), governo municipal (GM) e consolidado da administração pública por modalidades de aplicação em 2009.

\begin{tabular}{|c|c|c|c|c|}
\hline Modalidade de aplicação & GF & GE & GM & Consolidado \\
\hline Transferências à União & - & 117,81 & 27,84 & 145,64 \\
\hline $\begin{array}{l}\text { Transferências a estados e } \\
\text { ao DF }\end{array}$ & 8232,74 & - & 17,13 & 8249,87 \\
\hline $\begin{array}{l}\text { Transferências a } \\
\text { municípios }\end{array}$ & 11738,66 & 2860,73 & 11,18 & 14610,56 \\
\hline $\begin{array}{l}\text { Transferências a } \\
\text { instituições privadas sem } \\
\text { fins lucrativos }\end{array}$ & 777,05 & 1332,33 & 141,55 & 2250,93 \\
\hline $\begin{array}{l}\text { Transferências a } \\
\text { instituições privadas com } \\
\text { fins lucrativos }\end{array}$ & 3,86 & 62,13 & 7,87 & 73,85 \\
\hline $\begin{array}{l}\text { Transferências a } \\
\text { instituições } \\
\text { multigovernamentais } \\
\text { nacionais }\end{array}$ & 52,94 & 40,89 & 4,97 & 98,80 \\
\hline $\begin{array}{l}\text { Transferências a consórcios } \\
\text { públicos }\end{array}$ & - & 16,84 & 3,17 & 20,01 \\
\hline Transferências ao exterior & 3,33 & 0,77 & 1,78 & 5,88 \\
\hline Aplicações diretas & 25002,52 & 33502,12 & 24191,96 & 82696,59 \\
\hline $\begin{array}{l}\text { Aplicação direta operações } \\
\text { intraorçamentárias }\end{array}$ & 37,67 & 42,11 & 42,83 & 122,61 \\
\hline Investimentos & 45848,76 & 37975,72 & 24450,28 & 108274,76 \\
\hline
\end{tabular}

Nota: Valores empenhados em R\$ milhões.

Um segundo aspecto diz respeito aos itens que são contabilizados como

\footnotetext{
${ }^{3}$ Os dados desta seção são principalmente do arquivo Consolidação das Contas Públicas (CCP) da STN — ainda não atualizada para 2010. Suas informações são provenientes das bases de dados desagregadas: EOE e o banco de dados Finanças do Brasil: Dados Contábeis dos Municípios (Finbra). Para os governos federal e estadual, são complementadas com a EOE e o Siafi em 2010 e nas aplicações diretas de 2002 e 2003. As informações dos municípios são de versões mais recentes do Finbra com maior cobertura do que as versões utilizadas na CCP. As informações de 2002 e 2003 são do total e não das aplicações diretas, detalhe pouco importante nos municípios (ver Tabela 2). Todas as informações estão disponíveis em ht tp: / / www . tesouro. fazenda.gov.br/.
} 
"investimentos", mas que não deveriam ser classificados como despesas de capital fixo propriamente ditas. Sobre este ponto, um avanço importante foi a atualização do conceito de investimento na Portaria da STN/SOF de 2001, em relação à Lei de Finanças Públicas de 1964, que passou a não mais incluir as despesas com a constituição ou aumento do capital de empresas industriais e agrícolas. Estas despesas passaram a ser exclusivamente classificadas como inversões financeiras, o que é compatível com o conceito das contas nacionais. ${ }^{4}$ Ainda assim, os "investimentos" da contabilidade pública podem incluir itens que, por critério de contabilização mais específico, não se enquadram na definição de FBCF. Uma análise mais precisa nessa direção envolve considerar o terceiro e quarto níveis de classificação na Figura 1, denominados "elemento de despesa", e seu desdobramento ou "subelemento de despesa", os quais identificam com mais precisão o objeto do gasto.

A Tabela 3 mostra os principais elementos de despesa das aplicações diretas em investimentos. Verifica-se que aproximadamente $91 \%$ dos investimentos estão concentrados nos elementos típicos da FBCF, a saber: obras e instalações, equipamentos e material permanente e aquisição de imóveis ligados a uma obra. A ocorrência de despesas que não se enquadram nestes elementos não significa necessariamente que não integrem a FBCF. Para exemplificar, é comum que determinadas obras da União sejam realizadas pelas Forças Armadas com pessoal próprio e, portanto, relacionadas com despesas de material de consumo ou até diárias e passagens. Também é usual que despesas como a modernização de aeronaves militares sejam realizadas por serviços de terceiros de pessoa jurídica - procedimento este compatível com a definição da FBCF do IBGE apresentada na Tabela 1, que inclui o valor dos serviços ligados a melhorias que elevam a vida útil dos ativos existentes. É claro que sempre se pode questionar a contabilização de softwares e equipamentos militares como FBCF, mas isto não está em desacordo com as recomendações internacionais. ${ }^{5}$

Por outro lado, os elementos típicos também podem conter despesas que não são FBCF no sentido estrito, como é o caso dos "equipamentos e material permanente" na contabilidade pública, item que inclui desde máquinas e aeronaves até armamentos, aparelhos e utensílios domésticos, utensílios de escritório e mobiliário em geral. ${ }^{6}$ Estes últimos não condizem com o conceito utilizado pelo IBGE (2008a, p. 36) que exclui da FBCF o valor da aquisição de pequenos equipamentos. A contabilização mais precisa da FBCF exige, portanto, uma abertura mais detalhada do último nível de classificação da despesa, o subelemento. Sabe-se que o IBGE utiliza a classificação por natureza de despesa, inclusive ao nível do elemento (e talvez do subelemento de despesa), no seu processo de classificação das despesas públicas nas contas

\footnotetext{
${ }^{4}$ Para uma discussão mais detalhada, ver Costa (2008). Entretanto, existem indícios de que a constituição/aumento do capital de empresas industriais e agrícolas continue sendo contabilizada como investimento, principalmente nos governos subnacionais

${ }^{5}$ A contabilização de equipamentos militares na FBCF está prevista no SCN da ONU (1993), sob o argumento de que ampliam a capacidade de prover o serviço de segurança nacional, e adotada por países como os Estados Unidos, mas não nos principais países europeus que os contabilizam como consumo intermediário. A direção é no sentido de padronizá-los como investimento na próxima versão do SCN da ONU, prevista para 2012. Já os softwares, que são FBCF nas contas nacionais, normalmente são contabilizados pelo setor público, mas não pelas empresas privadas (ver Lequiller \& Blades 2006, p. 419). Estes problemas afetam a comparabilidade e eventuais estudos mais específicos sobre o impacto econômico dos investimentos públicos, mas não estão em desacordo com as práticas internacionais.

${ }^{6}$ Segundo a definição na Portaria Interministerial no 163, de 4 de maio de 2001, que dispõe sobre normas gerais de consolidação das contas públicas.
} 
Tabela 3: Elementos de despesa das aplicações diretas em investimentos do GF, GE, GM e consolidado da administração pública em 2009.

\begin{tabular}{|c|c|c|c|c|c|}
\hline $\begin{array}{l}\text { Elementos } \\
\text { de despesas }\end{array}$ & GF & GE & GM & Consolidado & $\begin{array}{l}\% \text { no } \\
\text { total }\end{array}$ \\
\hline $\begin{array}{l}\text { Obras e Instalações } \\
\text { Equipamento e } \\
\text { Material } \\
\text { Permanente }\end{array}$ & $\begin{array}{r}16219,13 \\
6030,91\end{array}$ & $\begin{array}{r}24179,05 \\
5791,36\end{array}$ & $\begin{array}{r}17840,43 \\
4002,33\end{array}$ & $\begin{array}{l}58238,61 \\
15824,60\end{array}$ & $\begin{array}{l}70,40 \\
19,10\end{array}$ \\
\hline $\begin{array}{l}\text { Outros Serviços de } \\
\text { Terceiros PJ }\end{array}$ & 1510,22 & 540,04 & 377,58 & 2427,84 & 2,90 \\
\hline $\begin{array}{l}\text { Aquisição de } \\
\text { Imóveis }\end{array}$ & 127,44 & 312,03 & 784,38 & 1223,85 & 1,50 \\
\hline $\begin{array}{l}\text { Sentenças Judiciais } \\
\text { Despesas de } \\
\text { Exercícios } \\
\text { Anteriores }\end{array}$ & $\begin{array}{c}0 \\
13,47\end{array}$ & $\begin{array}{l}711,85 \\
649,93\end{array}$ & $\begin{array}{l}254,25 \\
482,41\end{array}$ & $\begin{array}{r}966,10 \\
1145,81\end{array}$ & $\begin{array}{l}1,20 \\
1,40\end{array}$ \\
\hline $\begin{array}{l}\text { Indenizações e } \\
\text { restituições }\end{array}$ & 60,29 & 559,68 & 91,20 & 711,17 & 0,90 \\
\hline $\begin{array}{l}\text { Material de } \\
\text { Consumo }\end{array}$ & 545,46 & 94,55 & 117,14 & 757,15 & 0,90 \\
\hline $\begin{array}{l}\text { Serv. de } \\
\text { Consultoria }\end{array}$ & 253,95 & 118,83 & 24,39 & 397,17 & 0,50 \\
\hline Demais Elementos & 241,63 & 544,79 & 217,87 & 1004,29 & 1,20 \\
\hline Total & 25002,52 & 33502,12 & 24191,96 & 82696,59 & 100,00 \\
\hline
\end{tabular}

Fonte: Elaboração própria com as bases de dados descritas na nota de rodapé 3

Nota: Valores empenhados em R\$ milhões.

nacionais, além de dispor de pesquisas próprias mais detalhadas, sendo provável que realize um filtro para os investimentos de fato associados à FBCF. ${ }^{7}$ No entanto, tamanho grau de abertura é inviável com as bases de dados disponíveis ao público em geral, sobretudo nos governos subnacionais.

Outra operação difícil a partir das bases de dados públicas é a separação das receitas com a alienação de bens móveis e imóveis que devem ser deduzidas das despesas de investimento para o cálculo da FBCF. Como mostrado na Tabela 1, o conceito de FBCF faz menção ao resultado líquido das aquisições e vendas de ativos fixos pelo setor institucional. Daí a necessidade de deduzir as receitas obtidas pela APU com a venda ou cessão de bens móveis e imóveis, não integralmente, mas somente aquelas passíveis de serem classificadas como "ativos fixos utilizados repetida e continuamente em atividade produtivas". ${ }^{8}$ Infelizmente, as informações disponíveis nos relatórios orçamentários são sobre os agregados das alienações de bens móveis e de bens imóveis, não

\footnotetext{
${ }^{7}$ Ver especificamente o tradutor de despesas do plano de contas do governo no anexo 5 de IBGE (2008c), que identifica cada elemento de despesa do valor adicionado e do consumo intermediário das administrações públicas.

${ }^{8}$ É importante observar que nem todos os bens móveis e imóveis cedidos são passíveis de serem classificados como FBCF. Por exemplo, a cessão de um terreno que não será destinado à realização de uma atividade produtiva como a agricultura ou a uma obra deve ser classificado como cessão de ativo não financeiro e não FBCF.
} 
sendo possível discriminar aqueles que se enquadram no conceito de FBCF.

Por fim, deve-se ressaltar que os próprios conceitos de governo federal, estadual e municipal nas contas nacionais são distintos da contabilidade pública (Costa 2008). A principal diferença está relacionada ao tratamento dado às empresas estatais, uma vez que o IBGE classifica no setor institucional APU aquelas nas quais até $50 \%$ dos recursos advêm de transferências ou vendas de serviços a órgãos governamentais; enquanto aquelas cuja maior parte das receitas é proveniente de vendas ao público em geral são classificadas nos setores institucionais empresas financeiras ou não financeiras (IBGE 2008a, p. 83-84). Sendo assim, uma pequena parcela dos investimentos das empresas públicas também deve ser incluída na FBCF da APU (exemplo: Casa da Moeda), o que requer uma abertura detalhada do orçamento das empresas estatais, que é apresentado separadamente nos relatórios contábeis oficiais.

Em resumo, pode-se afirmar que o conceito de aplicações diretas em investimentos dos relatórios contábeis governamentais se aproxima, mas não é idêntico, ao de FBCF das APUs. A contabilização da FBCF exige uma abertura mais detalhada das despesas e receitas orçamentárias - exclusão de itens (subelementos) inapropriados, dedução da cessão de ativos fixos e inclusão de uma pequena parcela dos investimentos das empresas estatais - que não está acessível ao público em geral. Mesmo existindo diferenças, as informações apresentadas na Tabela 4 permitem concluir que são pouco significativas, quando se comparam os montantes de aplicações diretas em investimentos e a FBCF da APU nas contas nacionais. A tabela mostra os valores da FBCF da APU e as despesas de capital fixo da (extinta) publicação Finanças Públicas do Brasil, do IBGE que, diferentemente das contas nacionais, permite a desagregação entre os entes federados. ${ }^{9}$ Também estão reportados os montantes de aplicações diretas em investimentos dos governos federal, estadual e municipal.

Verifica-se na última coluna da Tabela 4 que é possível encontrar uma estimativa relativamente precisa dos números da FBCF da APU divulgados pelo IBGE a partir das informações dos demonstrativos contábeis da STN. O consolidado dos valores empenhados em aplicações diretas de investimentos (ou, no jargão contábil, o GND4 na modalidade de aplicação 90) é, em média, apenas cerca de $2 \%$ superior à FBCF da APU no período considerado. É claro que esta aproximação não é exata, pelos motivos explicitados anteriormente, mas possui a grande vantagem de desagregar a FBCF entre os entes federados.

Pode-se, assim, concluir que as diferenças conceituais entre a contabilidade pública e a contabilidade nacional e a limitação de acesso a informações com um grau de detalhamento inferior aos dados utilizados pelo IBGE não geram problemas consideráveis. A tradução do investimento da contabilidade pública para a FBCF da contabilidade nacional não é imediata, mas passível de ser operacionalizada ou ao menos bem aproximada. Entretanto, essas despesas são baseadas em valores empenhados e isso cria um problema conceitual e empiricamente sério, que será discutido na subseção 2.2 .

\footnotetext{
${ }^{9}$ Note-se que a FBCF da APU é um pouco inferior ao consolidado das despesas de capital fixo, pelo fato de que estas últimas não deduzem as cessões de ativos fixos e incluem despesas de ativos fixos que não fazem parte da FBCF, principalmente as despesas com aquisição de imóveis não ligados a uma obra (por exemplo, terrenos para a reforma agrária).
} 


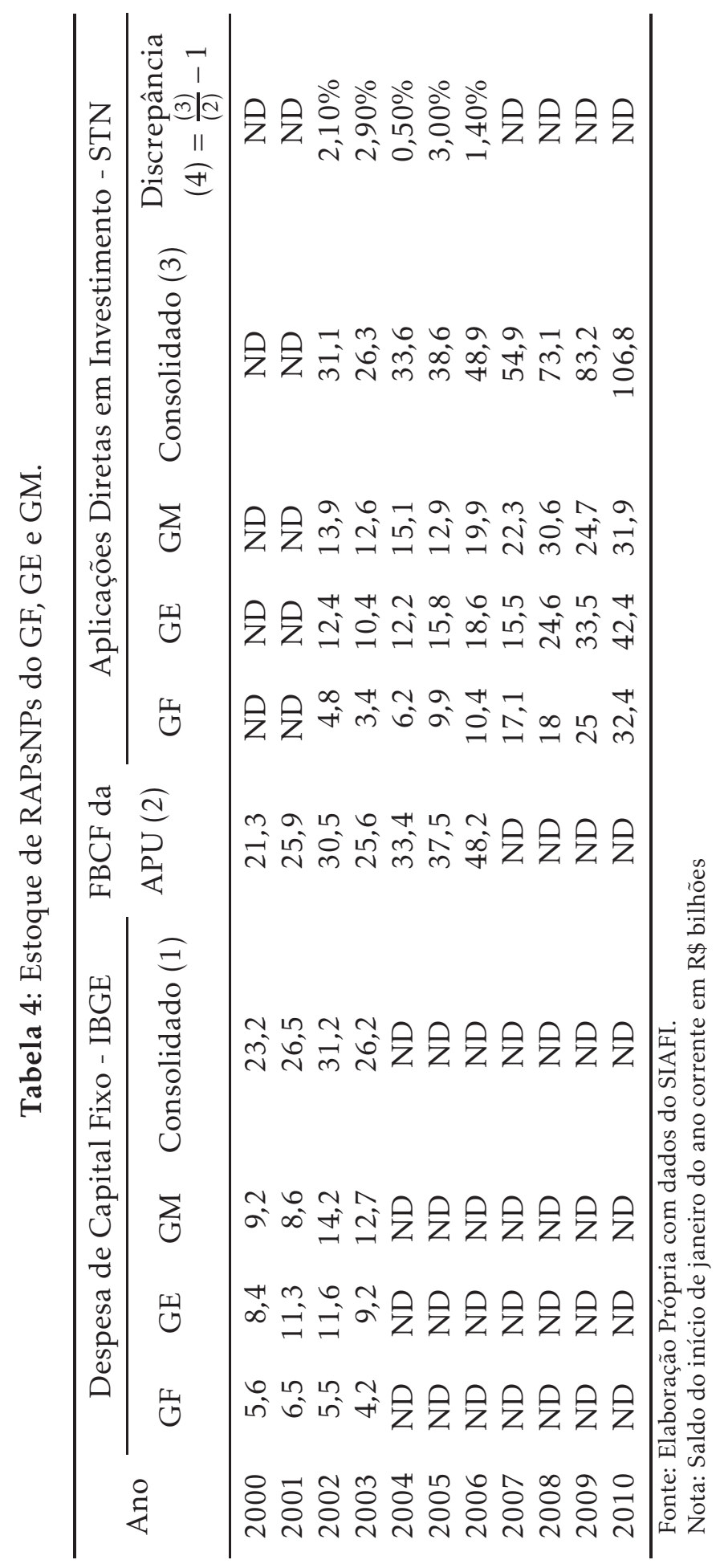




\subsection{Qual o critério mais apropriado de mensuração do investimento público? Conceitos básicos e a questão dos restos a pagar não processados (RAPsNPs)}

Não surpreende o fato de se encontrar uma aproximação bem razoável da FBCF da APU tomando-se os valores empenhados em aplicações diretas de investimentoss uma vez que o próprio IBGE utiliza os relatórios da contabilidade pública como fontes primárias. Mas afinal, o critério de empenho é a melhor maneira de mensurar as despesas para fins de cálculo da FBCF nas contas nacionais? A compreensão dessa questão envolve discutir previamente alguns conceitos básicos do processo orçamentário.

A despesa pública pode ser mensurada nas distintas etapas da sua execução, que inclui, resumidamente, os atos de empenho, liquidação e pagamento, explicitamente previstos na "Lei das Finanças Públicas" de 1964. De maneira simplificada, pode-se afirmar que o empenho corresponde à reserva de dotação orçamentária para a execução da despesa e provê garantias ao fornecedor de que existe crédito orçamentário para atendê-la. A liquidação ocorre imediatamente após a entrega da mercadoria ou a conclusão do serviço, momento no qual o governo verifica os documentos que comprovam que o fornecedor cumpriu devidamente suas obrigações. O governo assume a existência do direito adquirido pelo credor por receber o pagamento, correspondendo aos lançamentos na sua contabilidade de um passivo financeiro e, no caso dos investimentos, um ativo permanente. ${ }^{10}$ É nessa ocasião que há a transferência (formal) da propriedade do ativo fixo para a administração pública. O pagamento, por sua vez, é a última etapa, quando ocorre a emissão da ordem bancária de pagamento ou desembolso efetivo de recursos por parte da administração pública para saldar o compromisso com o credor.

Qual desses critérios é o mais apropriado para mensurar a FBCF da APU? Sobre esse aspecto, vale observar que a recomendação do SCN da ONU (1993) é particularmente clara: "o momento em que a FBCF deve ser contabilizada é quando a propriedade dos ativos fixos é transferida para a unidade institucional que tem a intenção de utilizá-los na produção. Com exceção dos ativos produzidos por conta própria, esse momento não é, em geral, o mesmo momento em que os ativos são produzidos. Nem é necessariamente o momento em que são colocados em uso no processo produtivo de outros bens e serviços" (tradução dos autores). A princípio, portanto, a resposta à pergunta é: utilizando-se os valores liquidados da execução das despesas governamentais, que estão em conformidade com a definição. ${ }^{11}$

\footnotetext{
${ }^{10}$ Esta afirmação se baseia na interpretação conjunta de vários artigos da Lei de Finanças Públicas, não exclusiva ao Artigo 58 que estabelece que o empenho cria para o Estado a obrigação de pagamento. Admite-se que esta obrigação é meramente contábil, mesmo que faça parte do passivo financeiro, pois condicionada à liquidação. Já o Artigo 62 estabelece que o pagamento somente pode ser ordenado após a liquidação — isto é, após a comprovação do cumprimento das obrigações por parte do fornecedor — quando se assume efetivamente a obrigação de pagamento.

${ }^{11}$ Vale um breve exemplo para melhor esclarecimento. A execução de uma obra pela administração pública (no caso mais geral) se inicia com uma pré-etapa de preparação do edital e de realização da licitação - finalizada quando se efetua o contrato entre o governo e a empresa vencedora da licitação que ficará responsável pela obra, estabelecendo as condições e os cronogramas de obras e desembolsos. O empenho antecede o início da obra e ocorre quando há a emissão da ordem de serviço para que a empresa contratada dê início às obras. Já a liquidação ocorre após a verificação de que a obra foi concluída e as obrigações contratuais, cumpridas, quando o governo assume formalmente o seu débito para com a empresa e a propriedade do ativo fixo em questão. Em condições normais, o pagamento tende a ocorrer pouco tempo após a liquidação.
} 
Infelizmente, isso não é sempre verdade, devido às peculiaridades do processo orçamentário brasileiro. Tais circunstâncias são importantes por enviesarem os dados liquidados em investimentos e têm a ver com a execução por inscrição em RAPsNPs. Os RAPsNPs correspondem a despesas que são empenhadas em um determinado ano e chegam ao final do exercício (31 de dezembro) sem terem sido sequer liquidadas, isto é, sem que a mercadoria tenha sido entregue ou o serviço sido concluído (ou ao menos sem que tenha havido tempo hábil de comprová-los). Note-se que a despesa, além de não ter sido paga, também não foi liquidada e por isso o "resto a pagar" a ela associado recebe a denominação "não processado".

A legislação orçamentária dispõe que os empenhos não liquidados devam ser cancelados no final do exercício fiscal, que coincide com o ano-calendário. Mas também prevê a possibilidade de que, nos casos em que a liquidação estiver em curso ou quando é de interesse da administração (entre outras situações especiais), a despesa seja executada por inscrição em RAPsNPs na virada do ano e sua validade prorrogada por mais 12 meses. Não havendo comprovação da entrega do produto ou conclusão do serviço dentro desse prazo, a legislação prevê ainda que haja cancelamento dos RAPsNPs e, por conseguinte, que essas despesas deixem de fazer parte do orçamento. Salvo o caso em que o chefe do Poder Executivo, por meio de decreto, autorize a reinscrição de RAPsNPs no dia 31 de dezembro do ano seguinte, caso em que os restos a pagar passam a ter validade prorrogada (normalmente por outros 12 meses).

As peculiaridades do processo orçamentário brasileiro decorrem, em primeiro lugar, do fato de que normalmente não há cancelamentos dos empenhos não liquidados - principalmente no âmbito do GF, mas também nos governos subnacionais - e a execução por inscrição em RAPsNPs se tornou generalizada (e não mais um ato discricionário). É exatamente esta inscrição automática em RAPsNPs de todos os empenhos não liquidados que Gobetti (2007) denominou liquidação forçada, ou seja, uma liquidação meramente contábil de uma despesa para a qual não houve efetivamente o reconhecimento do direito do credor. Adicionalmente, passou-se a fazer uso reiterado e de maneira não seletiva do dispositivo, por parte do chefe do Poder Executivo, que renova a validade dos RAPsNPs. ${ }^{12}$

A Figura 2 permite visualizar o procedimento de liquidação forçada no GF. Estão apresentados os valores acumulados ao longo do ano dos empenhos e das liquidações de aplicações diretas em investimentos. As liquidações (totais) correspondem à soma das liquidações do exercício e da execução por inscrição em RAPsNPs que ocorre no final do ano. Fica visível o grande descolamento, sempre nos meses de dezembro, entre as séries do liquidado do exercício e o total liquidado, bem como a virtual igualação deste último ao valor empenhado devido à liquidação forçada. Em outras palavras, os valores liquidados são artificialmente inflados e igualados aos empenhos no final do ano e correspondem a despesas para as quais não há comprovação da entrega do produto ou conclusão do serviço.

\footnotetext{
${ }^{12}$ Para um exemplo recente, ver as prorrogações na validade dos RAPsNPs por 12 meses nos decretos presidenciais: no 6.708, de 23 de dezembro de 2008; e no 7.057, de 29 de dezembro de 2009. Uma possível exceção teria ocorrido no último ano, quando o Decreto no 7.418 , de 31 de dezembro de 2010, renovou-os por apenas quatro meses e o Decreto no 7.468, de 28 de abril de 2011, condicionou a renovação às despesas cuja execução fosse iniciada até o mês de julho do ano, devendo-se cancelar os demais. Mas há indícios de que, devido a pressões do Congresso, a validade dos restos a pagar será novamente renovada de maneira não seletiva.
} 


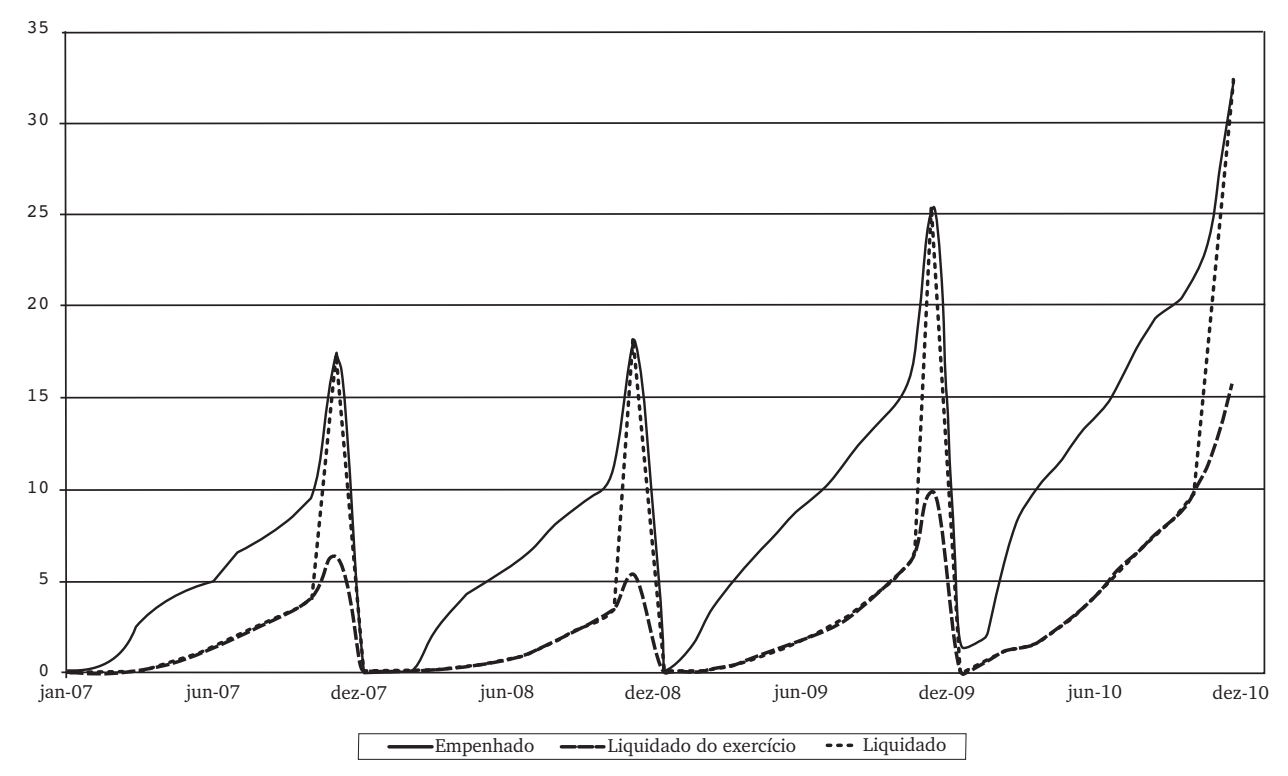

Fonte: Elaboração própria com os dados do Siafi

Figura 2: Execução orçamentária das aplicações diretas em investimento do GF (Valores acumulados no ano em R \$ bilhões)

Tabela 5: Estoque de RAPsNPs do GF, GE e GM.

\begin{tabular}{|c|c|c|c|c|}
\hline \multirow{2}{*}{ Ano } & \multirow{2}{*}{ GM } & \multirow{2}{*}{ GE } & \multicolumn{2}{|c|}{ GF } \\
\hline & & & Total & Invest. \\
\hline 2002 & 2,6 & 8,1 & 21,6 & 8,5 \\
\hline 2003 & 3,9 & 6,6 & 14,5 & 4,3 \\
\hline 2004 & 3,8 & 7,5 & 23,8 & 1,8 \\
\hline 2005 & 2,5 & 7,3 & 17,3 & 5,5 \\
\hline 2006 & 6,9 & 8,8 & 33,9 & 11,2 \\
\hline 2007 & 6,8 & 5,5 & 38,7 & 14,1 \\
\hline 2008 & 9,0 & 8,5 & 55,1 & 27,2 \\
\hline 2009 & 8,9 & 13 & 67,8 & 35,6 \\
\hline 2010 & 10,7 & 13,4 & 92,2 & 45,7 \\
\hline 2011 & 12,9 & 13,7 & 103,3 & 48,3 \\
\hline
\end{tabular}


Esse problema não seria tão sério se as despesas inscritas em RAPsNPs no final do ano fossem executadas no início (ou ao menos ao longo) do ano seguinte. Mas não é isso que tem ocorrido e a gravidade da distorção pode ser detectada pelo acúmulo dos RAPsNPs mostrado na Tabela 5. Observa-se que o problema é particularmente mais grave no GF, mas não se restringe a este ente federado. Em números, o estoque de RAPsNPs cresceu, entre os anos de 2005 e 2011, cerca de R\$ 86,0 bilhões no GF, R\$ 6,4 bilhões no GE, e R\$ 10,4 bilhões no GM. Um aspecto digno de nota é o peso dos investimentos no acúmulo de restos a pagar, responsável por quase metade da expansão do estoque de RAPsNPs do GF desde 2005, apesar da sua pequena importância no orçamento total. Fato esperado quando se trata de gastos como obras e instalações, que levam muito tempo para serem realizadas e com grande parcela de recursos orçamentários discricionários.

De todo modo, a noção a reter aqui é a de que a "inscrição em restos a pagar não processados" é um procedimento contábil criado precisamente para permitir que uma despesa empenhada em um exercício seja liquidada em um exercício posterior. O grande problema é que, diante das peculiaridades do processo orçamentário brasileiro, os empenhos tendem a ser majorados, liquidados automaticamente (por inscrição em RAPsNPs) — isto é, sem a comprovação da entrega do produto ou conclusão do serviço - e sucessivamente prorrogados de maneira não seletiva nos anos subsequentes (pela reinscrição de RAPsNPs). Ou seja, frequentemente são contabilizadas no orçamento de um determinado ano despesas que somente serão efetivadas vários anos depois ou mesmo projetos que não saíram ou não sairão do papel - constituindo-se mais propriamente em "restos a fazer" do que em "restos a pagar".

Daí a existência de uma distorção que enviesa as estatísticas oficiais de empenho e também de liquidação, uma vez que ambos são muitas vezes igualados artificialmente na presença da liquidação forçada e ainda é difícil discriminar a parcela referente à execução por inscrição em RAPsNPs. Não se deseja aqui esgotar o diagnóstico sobre os problemas do processo orçamentário brasileiro, o que será realizado em outra ocasião. O mais importante é perceber que o critério de empenho utilizado nos relatórios contábeis - e que serve de insumo para os cálculos do IBGE - tem se tornado cada vez mais inadequado para mensuração da FBCF, notavelmente quando se objetiva construir séries temporais de alta frequência com o objetivo de empregá-las na pesquisa macroeconômica.

Qual seria, então, a maneira mais apropriada para mensurar o investimento público? A primeira alternativa é adotar o critério de liquidação efetiva, que corresponde à soma das liquidações do exercício e das liquidações de restos a pagar, seguindo a nomenclatura de Gobetti (2007). Esse cálculo exige, em primeiro lugar, a obtenção das liquidações do exercício, por meio da exclusão (quando for o caso) da parcela referente à execução por inscrição em RAPsNPs no mês de dezembro. Em segundo lugar, deve-se considerar não apenas os valores liquidados referentes à dotação orçamentária de cada ano, mas também as liquidações de restos a pagar, que ocorrem quando é comprovada a entrega do produto ou a conclusão do serviço, referentes aos restos a pagar não processados, que passarão a compor os restos a pagar processados. Ou seja, é preciso adotar uma abordagem plurianual, tendo em vista que os restos a pagar constituem despesas de exercícios anteriores e representam um verdadeiro orçamento paralelo que, muitas vezes, supera o próprio orçamento do exercício, como se pode observar na Figura 3. Caso contrário, ao se descon- 
siderar os restos a pagar, se estaria cometendo um erro de subestimativa (e não mais de superestimativa) da despesa, pois que se contabilizaria apenas uma parte do que efetivamente está sendo executado em cada período.

Contudo, a operacionalização desses procedimentos não é trivial, como será visto mais adiante. Por isto, as alternativas mais acessíveis para mensurar a despesa que podem prover boas aproximações são: o critério de pagamento efetivo, que inclui os desembolsos financeiros para quitação dos compromissos do exercício e dos restos a pagar processados ou não processados (ver Gobetti 2007, Gobetti \& Orair 2010), e, no limite, a combinação dos pagamentos de RAPsNPs com as liquidações do exercício. Tais métodos oferecem um resultado final bastante próximo ao obtido com as liquidações efetivas, como se pode verificar pela comparação entre as séries de pagamentos e liquidações (efetivas, do exercício e de restos a pagar) na Figura 3.

Em outras palavras, a adoção do regime de caixa parece prover boas aproximações da liquidação efetiva, possibilidade que também é prevista nos manuais de contabilidade nacional para minimizar grandes distorções e constitui, portanto, um critério mais prático para a mensuração do investimento em frequência mensal. ${ }^{13}$ Obviamente, a escolha por algumas destas alternativas dependerá das informações disponíveis. ${ }^{14}$
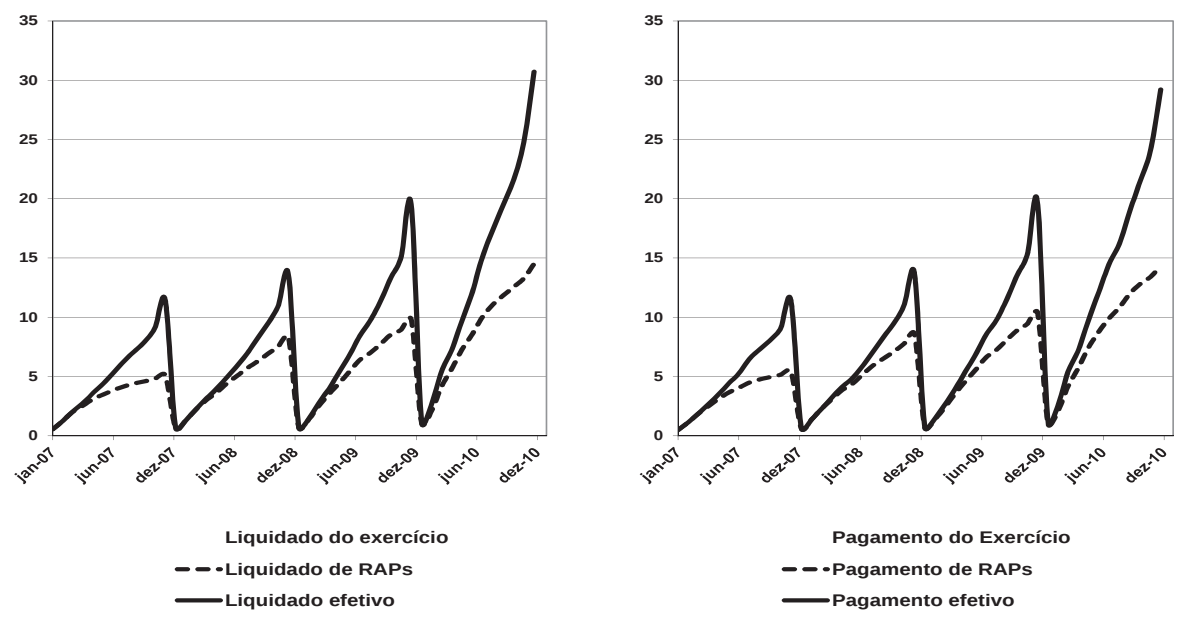

Fonte: Elaboração própria com os dados do Siafi

Figura 3: Execução orçamentária das aplicações diretas em investimentos do GF (Valores acumulados no ano em R\$ bilhões)

\footnotetext{
${ }^{13}$ Segundo o manual de contas trimestrais FMI (2001, p. 76), "A aplicação dos princípios contábeis no regime de competência aos dados trimestrais (...) pode apresentar problemas conceituais e práticos tão graves que podem se converter em um obstáculo para completar os dados. Nestes casos, talvez seja melhor publicar os dados no regime de caixa e mencionar com clareza os problemas (...)"

${ }^{14}$ Ressalte-se que a liquidação efetiva - que se refere àquela vinculada à comprovação da entrega do produto ou conclusão do serviço, em oposição à liquidação forçada - implica o reconhecimento formal de uma dívida da administração pública com seus fornecedores, mas não o pagamento imediato. Normalmente, o prazo para o pagamento não é muito longo, exceto em situações especiais como durante os contingenciamentos orçamentários que tendem a postergá-los. Nestas ocasiões, as informações de pagamentos se distanciam temporariamente das liquidações efetivas. Ainda assim, são mais precisas do que os empenhos.
} 


\subsection{Como o IBGE calcula a FBCF total da economia? Ou por que a eliminação do viés que superestima o investimento público não parece modificar o cálculo da FBCF total}

Na subseção anterior argumentou-se que é mais adequado mensurar a FBCF da APU pelo critério de liquidação efetiva (ou suas aproximações), de modo a eliminar as distorções presentes nas estatísticas oficiais e prover estimativas mais precisas. Mas resta o questionamento: qual a consequência desse ajuste sobre a FBCF total da economia? Felizmente para os propósitos do trabalho, eventuais mudanças nos critérios de mensuração da FBCF das APUs parecem ter impacto negligenciável no cálculo da FBCF total da economia, tanto em bases anuais quanto trimestrais.

A estimação da FBCF pelo IBGE nas contas nacionais se baseia, simultaneamente, nas informações da oferta de bens e serviços destinados a esta finalidade e na sua demanda, que corresponde aos investimentos produtivos realizados pelos setores institucionais (IBGE 2008a, p. 66). A princípio, estas informações são submetidas a análises de coerência e ao processo de equilíbrio de recursos e usos (ou entre demanda e oferta), podendo-se modificar os valores iniciais. No entanto, o próprio IBGE admite explicitamente que, em função da maior robustez das informações dos bens de capital pela ótica da oferta, sua disponibilidade é levada em consideração como referência no equilíbrio da FBCF e, na prática, são as demandas dos setores institucionais que passam pelos processos de correção (IBGE 2008a).

Também é prática comum entre os compiladores das contas nacionais que utilizem como referência as informações da administração pública (e também do balanço de pagamentos), já que apresentam uma melhor cobertura (FMI 2001, p. 49). Os setores institucionais das empresas e das famílias, formados por milhões de unidades, nas quais é muito mais difícil dispor de estatísticas confiáveis e uma cobertura adequada, terminam sofrendo os principais ajustamentos no processo de equilíbrio de demanda e oferta nas contas nacionais. Este parece ser o caso do Brasil, o que pode explicar a precisão encontrada entre os dados de investimento da contabilidade pública e as estimativas da FBCF da APU, juntamente com a referência explícita de que a oferta de bens de capital é "levada em consideração como referência no equilíbrio da FBCF". Em outras palavras, a leitura dos relatórios metodológicos parece indicar que eventuais imprecisões nas estimativas da FBCF da APU tenham como contrapartida ajustes correspondentes que modificam a FBCF dos demais setores institucionais de maneira a assegurar o equilíbrio de recursos e usos. ${ }^{15}$

Visto por outro ângulo, parece-nos que a adoção de um critério mais preciso de cálculo da FBCF da APU tem impacto fundamentalmente sobre a repartição da FBCF entre os setores institucionais, mas não sobre o seu patamar. $\mathrm{O}$ que pode inclusive melhorar a estimativa da FBCF dos demais setores institucionais (empresas e famílias).

\footnotetext{
${ }^{15} \mathrm{O}$ fato de se tratar de séries de alta frequência da FBCF da APU também parece não ocasionar problemas mais sérios. A metodologia das contas nacionais trimestrais sequer faz referência às informações da demanda dos setores institucionais na estimação dos indicadores conjunturais da FBCF, baseando-se fundamentalmente nas variáveis de oferta, a saber, o índice de volume da produção e das importações dos bens destinados a esta finalidade e os respectivos índices de preços IBGE (2008b). Além disso, os valores de referência da FBCF nas contas nacionais trimestrais são advindos das contas nacionais anuais.
} 


\section{Estimativas de alta frequência da FBCF das administrações públicas para o período 2002-2010}

Resumindo os principais argumentos feitos até aqui, pode-se afirmar que é possível, a partir das informações dos principais relatórios contábeis governamentais, obter estimativas razoavelmente próximas aos números divulgados pelo IBGE para a FBCF da APU. No entanto, as estimativas se baseiam nos valores de empenho e apresentam distorções que afetam as informações de execução dos investimentos ao longo do ano, o que é particularmente grave, quando se deseja estimar séries de alta frequência para serem utilizadas na pesquisa macroeconômica aplicada. Com o intuito de contornar esse problema, mostrou-se que o critério mais adequado para mensurar a FBCF da APU é a liquidação efetiva (ou suas aproximações a partir das informações de pagamentos) e que uma eventual utilização deste critério não gera distorções aos dados da FBCF da economia, mas somente altera a sua repartição entre os setores institucionais.

Esta seção descreve brevemente os procedimentos de estimação das séries mensais da FBCF da APU no período 2002-2010. Em realidade, trata-se de uma aproximação com as liquidações efetivas em aplicações diretas de investimento de cada ente federado que, por simplicidade, será referida nesta seção como FBCF. Para o GF é possível dispor das séries em periodicidade mensal extraídas diretamente do Siafi. Os conceitos relevantes já foram apresentados em Gobetti (2007) e séries mensais em Gobetti \& Orair (2010). ${ }^{16}$

As maiores dificuldades estão relacionadas à carência das informações dos governos subnacionais. A principal fonte de informações de alta frequência das finanças públicas dos governos subnacionais são os Relatórios Resumidos de Execução Orçamentária (RREOs). Cumpre, no entanto, ressaltar que existem limitações das informações contidas nesses relatórios quando se deseja estimar a FBCF. ${ }^{17}$ Ademais, não se deve negligenciar as dificuldades relativas ao formato de difícil manipulação (arquivos em pdf), às informações ausentes, inconsistências e problemas de cobertura, particularmente mais graves nos anos iniciais da amostra e para os municípios. Os RREOs proveem informações extremamente úteis, mas desde que complementados por informações de outras fontes, submetidos a testes de consistência e, no caso dos municípios, que se trabalhe com uma amostra aleatória (ver, Orair et al. 2011).

Diante de todas estas dificuldades, optou-se por solicitar informações dire-

\footnotetext{
${ }^{16}$ A contabilidade da STN/MF passou a disponibilizar uma consulta no Siafi Gerencial tanto para os valores da liquidação efetiva quanto do pagamento efetivo, o que facilita o acesso às informações. Mas são pouco utilizadas pelos órgãos governamentais e nos demonstrativos contábeis.

${ }^{17}$ Os RREOs, previstos no Artigo 165 da Constituição Federal e regulamentados pela LRF, devem ser encaminhados bimestralmente pelos governos dos três entes federados à STN, sob risco de punições fiscais e penais, e disponibilizados em meios de amplo acesso público. É possível, a partir destes relatórios, construir séries bimestrais das despesas de investimentos liquidadas no exercício e dos pagamentos (totais) de RAPsNPs. Entretanto, estas informações não estão abertas por modalidade de aplicação e, no caso dos restos a pagar, não se dispõe das liquidações (somente pagamentos) e nem das informações de grupo de despesa. Adicionalmente, as informações do período anterior a 2006 não permitem discriminar as liquidações do exercício da execução por inscrição em RAPsNPs - o que modificou desde a Portaria no 633 da STN, de 30 de agosto de 2006, que estabeleceu sua discriminação para conferir maior transparência, a partir de 2007, com informações retroativas a 2006. É possível no máximo obter aproximações da FBCF, já que este conceito exige dispor das aplicações diretas de investimentos referentes a: i) liquidações do exercício, que não incluem a execução por inscrição de RAPsNPs; e ii) liquidações de restos a pagar.
} 
tamente a quase duas centenas de contadores públicos, técnicos ou secretários de Fazenda/Planejamento estaduais e municipais (ver o Apêndice B para mais detalhes). Durante os primeiros contatos com os órgãos competentes, ficou claro que podem existir dificuldades de caráter operacional para a obtenção das liquidações de restos a pagar em um grande número de governos estaduais e prefeituras. Por outro lado, a série de pagamentos está mais acessível. Optou-se assim por solicitar informações que viabilizem também o cálculo de aproximações alternativas da FBCF — isto é, das liquidações efetivas - a partir das informações de pagamentos, conforme discutido na subseção 2.2.

Os procedimentos adotados na construção das séries da FBCF dos governos subnacionais no período 2002-2010 estão brevemente descritos no Apêndice A. Por limitações de espaço e para manter o escopo, não se deseja entrar nos pormenores metodológicos. O que se deve ressaltar é que foi possível construir uma série mensal da FBCF de uma amostra de 15 estados, do DF e de 30 municípios de grande porte, sobretudo capitais, que enviaram informações de boa qualidade, após um árduo trabalho de convencimento com os responsáveis pelos órgãos competentes. As estimativas deste trabalho indicam que as amostras cobrem aproximadamente $74 \%$ da FBCF do GE e 20\% do GM no período de 2002 a 2010.

Para os demais estados e municípios, não foi possível formar as séries mensais de maneira direta. A primeira razão é porque estava fora do alcance da pesquisa cobrir a totalidade dos municípios do país de modo que o foco inicial recaiu sobre aqueles mais representativos. Em segundo lugar, porque alguns estados e municípios contatados não responderam ou não enviaram informações de boa qualidade e, em alguns casos, somente disponibilizaram informações anuais. Sendo assim, foi necessário um esforço adicional de estimação das séries relevantes e uso de técnicas de desagregação temporal para construir as séries mensais dos estados e municípios não cobertos pela amostra. ${ }^{18}$

No caso dos governos estaduais, é possível completar e estimar as informações nos 11 estados ausentes da amostra e, assim, consolidar a série da FBCF - ainda que tenha sido necessário utilizar procedimentos de estimação não triviais e explicitados no Apêndice A. Já na esfera municipal há um problema adicional que é a impossibilidade, a partir das atuais bases de dados disponíveis, de dispor de séries de alta frequência para os milhares de municípios do país. Mesmo o Finbra, que é um banco de dados de frequência anual disponibilizado pela STN, possui uma cobertura incompleta. Daí a combinação de procedimentos de imputação para complementação das informações ausentes e desagregação temporal para formar séries mensais a partir das informações do Finbra. ${ }^{19}$

\footnotetext{
${ }^{18} \mathrm{~A}$ desagregação temporal corresponde à estimação de dados intraperíodo da série objetivo, disponível de forma agregada temporalmente, utilizando a informação de indicadores relacionados na (alta) frequência desejada e sujeita à restrição de que sua soma iguale o valor de referência da série objetivo. Seguiu-se uma abordagem semelhante às de Orair et al. (2011) e Dias et al. (2010) que utilizam indicadores obtidos das informações de uma amostra de municípios. A exemplo de Dias et al. (2010), a desagregação temporal foi ajustada por modelos de espaço-estado, baseados no filtro de Kalman. Sua grande vantagem é a flexibilidade, permitindo também outras operações como a imputação (estimação de variáveis ausentes), que também foi utilizada. A metodologia de estimação das séries da FBCF dos governos subnacionais está descrita com mais detalhes em Orair \& Silva (2012).

${ }^{19}$ Seguiu-se a metodologia apresentada em Orair et al. (2011) para complementar as informações do Finbra e, em seguida, desagregá-las para a frequência bimestral fazendo-se uso de indicadores relacionados das liquidações bimestrais do exercício de 297 municípios selecionados por amostragem aleatória estratificada. Na etapa seguinte, foi aplicada a desagregação temporal
} 
A sazonalidade da série mensal dos investimentos municipais foi obtida principalmente das informações de liquidações do exercício, o que minimiza o problema das distorções dos valores empenhados sobre a execução dos investimentos ao longo do ano. Contudo, os procedimentos de desagregação temporal somente formam uma série mensal a partir dos valores empenhados de referência do Finbra que, conforme observado anteriormente, não é o critério mais preciso para fins de cálculo da FBCF. Com intuito de mitigar parcialmente esse problema, foi realizado um ajuste para que - no caso exclusivo dos 30 municípios de grande porte para os quais se dispõem de informações de boa qualidade - seja considerado o critério de liquidação efetiva que é mais preciso. Mesmo que constitua uma amostra restrita em número de municípios, seu peso sobre os investimentos municipais é relativamente significativo, por se tratar de municípios de grande porte, que representam cerca de $20 \%$ do total da FBCF do GM.

Ressalte-se, entretanto, que esta amostra formada por municípios de maior porte com informações de boa qualidade será, muito provavelmente, enviesada. Espera-se que os menores municípios - e até mesmo os maiores municípios que não enviaram informações de boa qualidade - possuam processos diferenciados de execução das suas despesas orçamentárias. Sem dúvida, esta é uma limitação e provê margem para possíveis avanços na metodologia de estimação apresentada neste trabalho. O que pode ocorrer tanto pela ampliação da amostra de municípios considerados, que envolve requisitos operacionais e humanos não triviais, quanto pela adoção de critérios mais adequados de contabilização e maior transparência na execução do orçamento de restos a pagar por parte dos órgãos contábeis das administrações públicas. Feita esta ressalva, não se deve deixar de ressaltar os méritos por se ter adotado critérios mais precisos para a estimação das séries mensais da FBCF no GF, GE e uma parcela importante do GM. Ao final de todos os procedimentos, foi possível obter estimativas da FBCF dos três entes federados na Tabela 6 e as séries mensais da FBCF da APU nas Figuras 4 e 5. A Tabela 6 permite comparar os valores encontrados a partir das informações presentes nos relatórios contábeis da STN e aqueles estimados pela metodologia apresentada neste trabalho.

Os resultados apresentados na Tabela 6 sugerem que o total da FBCF da APU nas estatísticas oficiais da STN tenha sido superestimado em $11 \%$ no período de 2002 a 2010, problema que é mais grave no GF com superestimação de $19 \%$, seguido do GE de $7 \%$, e da amostra do GM em $5 \%$. Note-se que o viés nem sempre é de superestimação, podendo ainda haver subestimação do investimento público como mostram as informações do GM nos anos de eleições municipais (2004 e 2008). ${ }^{20}$ De fato, há evidências de uma relação entre ciclo eleitoral e aceleração da execução dos investimentos nos três entes federados incluindo-se aqui a execução dos restos a pagar de exercícios anteriores -, que faz com que as estimativas próprias da FBCF nos anos não eleitorais (ímpares) tenham apresentado uma média de $\mathrm{R} \$ 5,3$ bilhões abaixo dos valores da STN, que corresponde a quase o dobro da média de $\mathrm{R} \$ 2,7$ bilhões nos anos

por modelo de espaço de estado para obter a série mensal dos investimentos dos municípios (ver o Apêndice A). Até o ano de 2008 os arquivos da EOE e do Finbra se baseavam apenas em valores de empenho. Desde 2009, passaram a apresentar os valores liquidados e pagos no exercício, mas que, conforme abordado na subseção 2.2, são pouco úteis para o trabalho, pois subestimam os montantes de investimentos.

${ }^{20}$ Ressalte-se que o ano de 2002 no GF foi atípico (Gobetti 2007). 
Tabela 6: Estimativas da FBCF do GF, GE e amostra do GM* a partir das informações dos principais relatórios contábeis da STN e pela metodologia descrita neste trabalho - Valores em R B Bilhões.

\begin{tabular}{|c|c|c|c|c|c|c|c|c|c|}
\hline \multirow[t]{2}{*}{ Ano } & \multicolumn{3}{|c|}{ FBCF - STN } & \multicolumn{3}{|c|}{$\begin{array}{c}\text { FBCF } \\
\text { Estimativa própria }\end{array}$} & \multicolumn{3}{|c|}{$\begin{array}{c}\text { Diferença entre } \\
\text { as estimativas }\end{array}$} \\
\hline & GF & GE & $\overline{\mathrm{GM}^{*}}$ & GF & GE & $\mathrm{GM}^{*}$ & $\overline{G F}$ & GE & $\mathrm{GM}^{\star}$ \\
\hline 200 & 4,8 & 12,4 & 2,6 & 6,7 & 12 & 2,3 & $-1,9$ & 0,4 & 0,3 \\
\hline 200 & 3,4 & 10,4 & 8 & 3,4 & & 3,0 & 0,0 & 0,9 & 0,1 \\
\hline 200 & 6,2 & 12 & 3 & 4,2 & 11 & 3,7 & 2,0 & 0,4 & $-0,1$ \\
\hline 200 & 9 & 15 & 2 , & 7 & 1 & 1 , & 2,7 & 1,1 & 0,4 \\
\hline 200 & 10 & 18 & 1 & 9 & & 3 , & 1,2 & 0 & 0,3 \\
\hline 2007 & 17,1 & 15,5 & $4, \subseteq$ & 11,5 & 1 & 4,2 & 5,7 & 1,4 & 0,7 \\
\hline 2008 & 18,0 & 24,6 & 6,1 & 13,7 & 22,4 & 6,3 & 4,3 & 2,2 & $-0,3$ \\
\hline 2009 & 25,0 & 33,5 & 5,0 & 19,9 & 30,6 & 4,8 & 5,1 & 3,0 & 0,1 \\
\hline 2010 & 32,4 & 42,4 & 6,7 & 30,9 & 40,1 & 6,4 & 1,5 & 2,4 & 0,3 \\
\hline Tola & 127,2 & 185,4 & Jo,1 & 106,6 & נינד & 36,3 & 20 & 1 & 1,8 \\
\hline
\end{tabular}

Fonte: Elaboração própria com as bases de dados descritas na nota de rodapé 3 e na metodologia descrita no anexo.

Nota: Considera-se uma amostra de governos de 30 municipios de grande porte

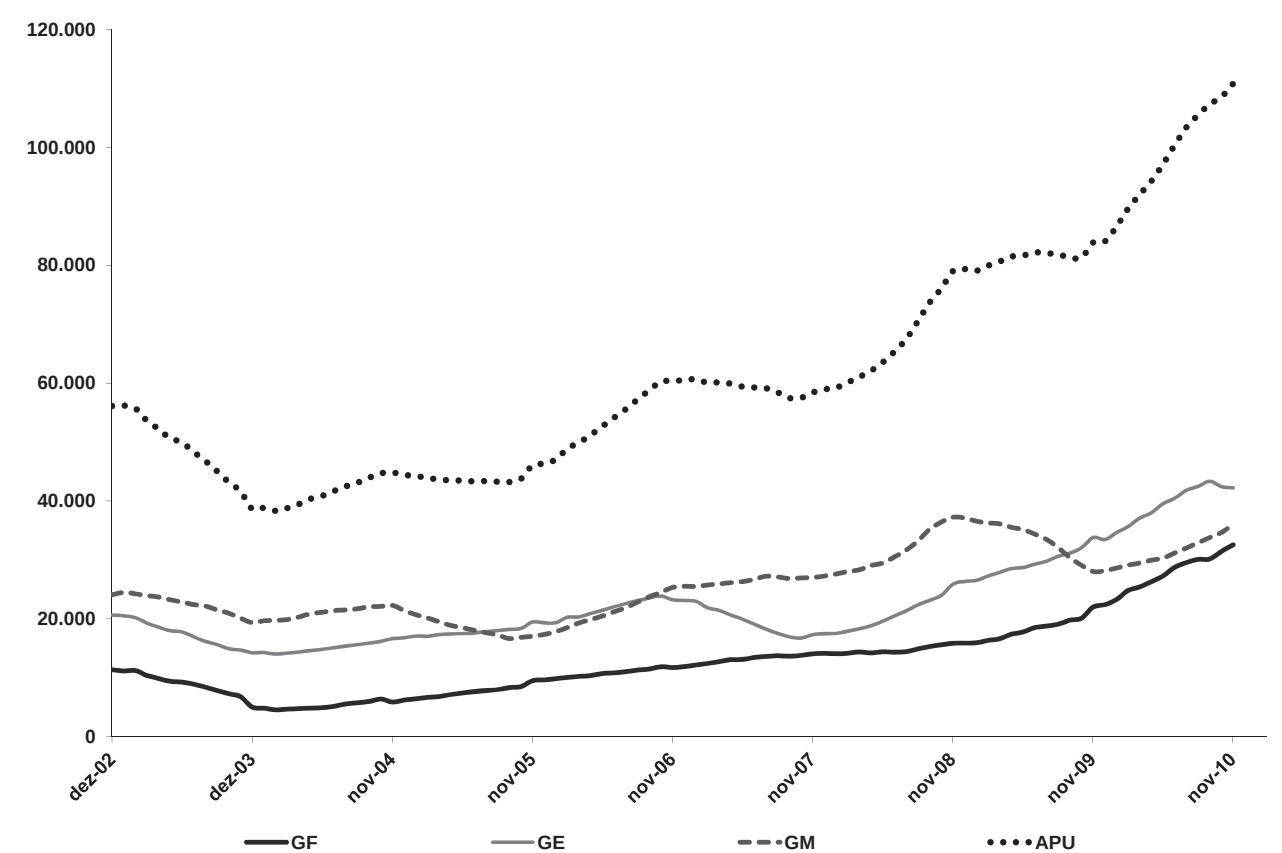

Fonte: Elaboração própria com a metodologia apresentada no Apêndice A

Figura 4: Estimativas da FBCF do GF, GE, GM e consolidado da APU - Valores acumulados em 12 meses em R\$ milhões de fevereiro de 2011, deflacionados pelo IPCA 


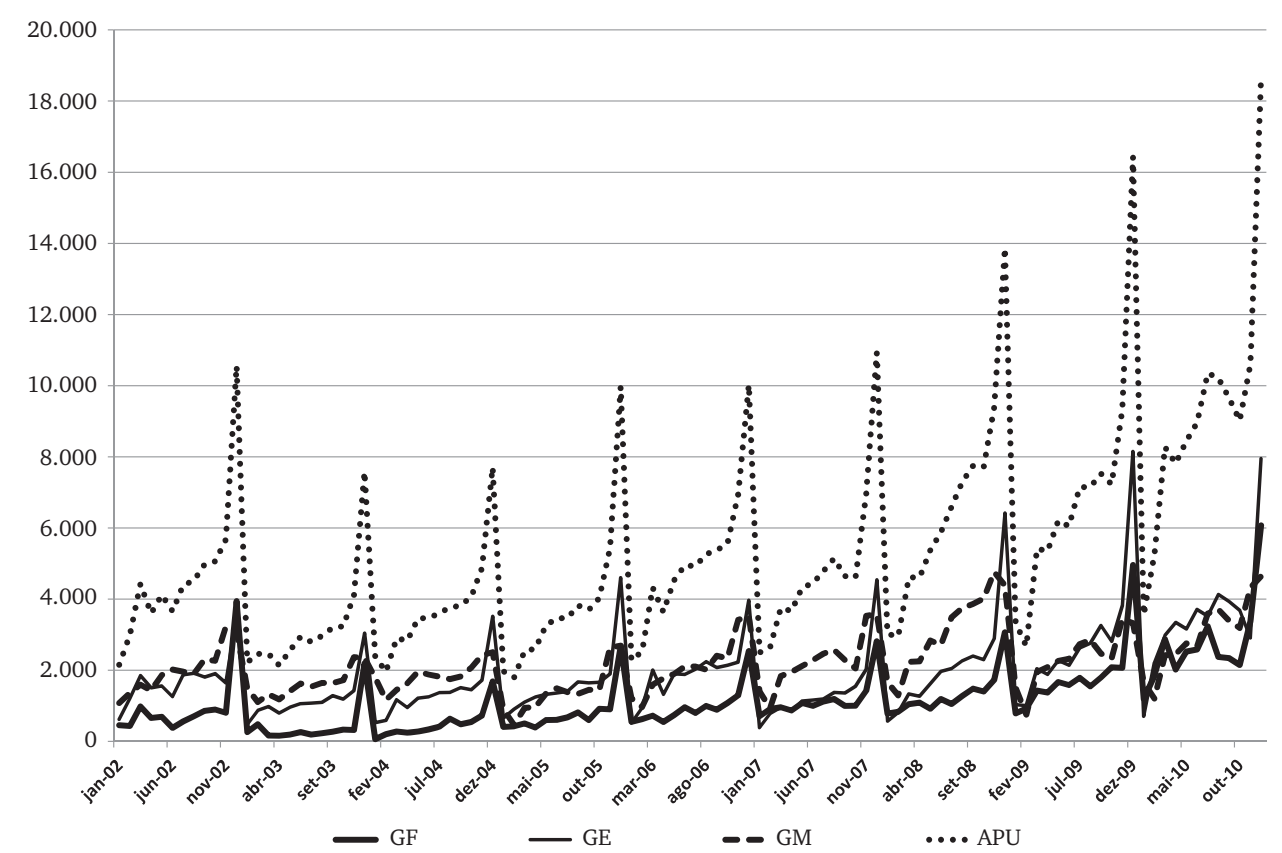

Fonte: Elaboração própria com a metodologia apresentada no Apêndice A

Figura 5: Estimativas da FBCF do GF, GE, GM e consolidado da APU - Valores em R $\$$ milhões de fevereiro de 2011, deflacionados pelo IPCA

eleitorais (pares). ${ }^{21}$

Esta relação também está evidenciada na taxa de crescimento da FBCF. Como mostrado no Figura 4, a FBCF da APU cresceu fortemente no período recente, quase triplicando ao passar do patamar de $\mathrm{R} \$ 38,7$ bilhões em 2003, após o ajuste fiscal do primeiro ano do governo Lula, para $\mathrm{R} \$ 110,8$ bilhões em 2010. A taxa de crescimento real da FBCF da APU foi próxima a $9 \%$ ao ano (a.a.), mas diferenciada entre os anos eleitorais (pares) e os demais (ímpares). A média da taxa de crescimento nos anos ímpares foi de $2 \%$ a,a. enquanto a dos anos pares foi de $29 \%$. É claro que esse número está influenciado pela queda do investimento dos municípios no ano de contágio da crise internacional no Brasil em 2009. Mas ainda assim sugere uma relação entre ciclo eleitoral e execução do investimento que não fica tão clara quando se analisam as estatísticas oficiais da STN. ${ }^{22}$

De qualquer maneira, evidencia-se uma retomada consistente da FBCF da APU nos últimos anos. Por fim, a Figura 5 permite uma análise da sazonalidade mensal da FBCF da APU, mostrando-se uma forte concentração nos últimos meses do ano e principalmente no mês de dezembro - mesmo depois do ajuste para expurgar a liquidação forçada neste mês -, o que pode ser parcialmente explicado pelo cronograma de liberação dos limites de em-

\footnotetext{
${ }^{21}$ Vale destacar que a execução do orçamento de restos a pagar de exercícios anteriores somente aparece nas estimativas da FBCF obtidas pela metodologia utilizada neste trabalho e não nas estatísticas da STN. A principal diferença é que as estimativas obtidas dos relatórios da STN incluem a execução por inscrição em RAPsNPs que é meramente contábil, isto é, despesas que serão de fato executadas somente nos anos seguintes ou sequer sairão do papel. Já a metodologia descrita neste trabalho procurou excluir estas despesas e incluir aquelas de orçamentos anteriores que efetivamente estão sendo executadas (liquidadas).

${ }^{22}$ Cumpre notar que outros pesquisadores - e.g. Cossio (2002) no caso dos governos estaduais e Sakurai (2007) no caso dos governos municipais — já destacaram anteriormente a importância dos ciclos eleitorais para as finanças públicas dos governos subnacionais brasileiros.
} 
penhos, liquidações e pagamentos por parte dos órgãos de planejamento, que são concentrados nos últimos meses do ano.

\section{Considerações Finais}

Este artigo se propôs a: i) examinar a compatibilidade entre os conceitos de "despesa de investimento" e "formação bruta de capital fixo da administração pública" (FBCF-APU), respectivamente da contabilidade pública brasileira e das contas nacionais (e de vários outros conceitos a eles relacionados); e ii) apresentar os procedimentos de estimação da FBCF-APU, mensal e desagregada por nível de governo, para o período 2002-2010.

Naturalmente, as estimativas apresentadas (no Apêndice C) e discutidas neste trabalho envolveram procedimentos de estimação não triviais (notadamente no caso dos governos subnacionais) e são, portanto, aproximações admitidamente imperfeitas da realidade. Ainda assim, e mesmo reconhecendo que há considerável espaço para aperfeiçoamento das estimativas aqui apresentadas, - e torcendo para que outros pesquisadores se interessem em aperfeiçoálas - acredita-se ter tomado cuidados suficientes para garantir que a "informação" contida supere em muito o "ruído" introduzido pelos erros de mensuração. Acredita-se, assim, que as estimativas sejam úteis - se utilizadas com suficiente critério - em análises econométricas e/ou históricas sobre a dinâmica da FBCF da APU (ou sobre variáveis dependentes desta última) no período em questão.

\section{Referências Bibliográficas}

Cavalcanti, M. A. F. H. (2000), 'Um modelo macroeconométrico trimestral para o brasil: possibilidades, limitações e resultados', Mimeografado . Rio de Janeiro: Ipea.

Cossio, F. A. B. (2002), Ensaios sobre federalismo fiscal no Brasil, PhD thesis, Pontifícia Universidade Católica do Rio de Janeiro, Rio de Janeiro.

Costa, M. B. (2008), Contabilidade governamental x contabilidade nacional: a mensuração do investimento público no brasil, Master's thesis, Instituto Serzedello Corréa do Tribunal de Contas da União. Especialização em Orçamento Público.

Dias, V. P., Issler, J. V. \& Rodrigues, C. (2010), Interpolação de variáveis fiscais brasileiras usando representação de espaço de estados, in 'Anais Eletrônicos do $38^{\circ}$ Encontro Brasileiro de Econometria', Salvador.

dos Santos, C. H. \& Costa, F. R. (2008), 'Uma metodologia de estimação da carga tributária bruta brasileira em níveis trimestrais', Economia Aplicada 12(4), 581-606.

dos Santos, C. H. M., Macedo e Silva, A. C. \& Ribeiro, M. B. (2010), 'Uma metodologia de estimação da carga tributária líquida brasileira trimestral no período 1995-2009', Economia Contemporânea 14(2), 209-236. Rio de Janeiro.

FMI (2001), Manual for quarterly national accounts: concepts, data sources, and compilation, Fundo Monetário Internacional - FMI, Washington. 
Gobetti, S. W. (2007), Estimativa dos investimentos públicos: um novo modelo de análise da execução orçamentária aplicado às contas nacionais, Editora da Universidade de Brasília, Brasília. SECRETARIA DO TESOURO NACIONAL (STN). Finanças Públicas. XI Prêmio Tesouro Nacional de Monografias em 2006.

Gobetti, S. W. \& Orair, R. (2010), Classificação e análise das despesas públicas federais pela Ótica macroeconômica (2002-2009), IPEA, Brasília. Texto para Discussão n. 1485.

IBGE (2008a), Sistema de Contas Nacionais, IBGE, Rio de Janeiro. Série Relatórios Metodológicos, n. 24.

IBGE (2008b), Contas Nacionais Trimestrais, IBGE, Rio de Janeiro. Série Relatórios Metodológicos, n. 28.

IBGE (2008c), Produto Interno Bruto dos Municípios, IBGE, Rio de Janeiro. Série Relatórios Metodológicos, n. 29.

Lequiller, F. \& Blades, D. (2006), Understanding National Accounts, OCDE Publishing.

Muinhos, M. K. \& Alves, S. A. L. (2003), Medium-size macroeconomic model for the Brazilian economy., Banco Central do Brasil, Brasília. Working Paper Series n.64.

ONU (1993), System of National Accounts, 1993, Organização das Nações Unidas - ONU, New York.

Orair, R., dos Santos, C. H. M., Silva, W. J., Brito, J. M. M., Ferreira, A. S., Silva, H. L. \& Rocha, W. S. (2011), 'Uma metodologia de construção de séries de alta frequência das finanças municipais no brasil com aplicação para o iptu e o iss (2004-2010)', PPE - Pesquisa e Planejamento Econômico 41(3).

Orair, R. \& Silva, W. J. (2012), Investimentos dos Governos Subnacionais no Brasil: Estimação e Análise por Modelos de Espaço de Estado, Ipea, Brasília. Texto para Discussão n. 1771.

Sakurai, S. N. (2007), Ciclos eleitorais, reeleição e déficit fiscal nos municípios brasileiros: uma análise via dados em painel, $\mathrm{PhD}$ thesis, Faculdade de Economia, Administração e Contabilidade Universidade de São Paulo, Brasil. Tese de Doutorado - (Doutorado em Teoria Econômica). 


\section{Apêndice A Procedimentos de estimação da série de alta frequência da FBCF dos governos subnacionais}

1. Solicitação de informações mensais de aplicações diretas de investimentos referentes aos: empenhos, liquidações e pagamentos do exercício separando-se a execução por inscrição em restos a pagar; e os pagamentos dos restos a pagar - se possível, discriminados em processados e não processados. Os contatos foram por ofício, correio eletrônico e telefonemas para os órgãos competentes dos estados, DF e 160 municípios que realizaram os maiores montantes de investimento no biênio 20072008 (tomando-se como base o valor do Finbra). Vinte e quatro estados (incluindo o DF) e 87 municípios atenderam às solicitações — ainda que apenas muito parcialmente e com informações anuais na maioria dos casos.

2. Testes de consistência, complementação com outras fontes e imputações das informações para 26 estados, DF e para os municípios que enviaram informações mensais. Os testes de consistência fazem a checagem da informação por comparação das redundâncias e análises de coerência (exemplo: comparação das informações enviadas com as que aparecem múltiplas vezes no RREO, algumas das quais implicitamente nas séries acumuladas no ano e do ano anterior, ou em fontes como a EOE, Finbra, Balanço Geral e sítios das secretarias de Fazenda; eliminação de equívocos comuns como a não exclusão das inscrições em restos a pagar processados (RAPs), nos separadores de milhares, informações de empenho onde deveria estar liquidação; análise de consistência entre as inscrições e liquidações de RAPs com as informações do seu estoque na EOE ou Finbra e no demonstrativo de RAPs do RREO, entre vários outros), permitindo-se a seleção das informações de boa qualidade, eliminação de equívocos comuns e complementação das séries com fontes de dados alternativas. Em alguns casos (principalmente nos anos extremos de 2002 e 2010), recorreu-se à imputação de informações ausentes com modelo de espaço de estado. Os procedimentos foram utilizados, em primeiro lugar, para selecionar e complementar as séries de boa qualidade em frequência mensal de 15 estados, DF e 30 municípios. Em seguida, foram utilizados para formar as séries anuais das liquidações efetivas em aplicações diretas de investimentos dos 11 estados não cobertos pela amostra. Em algumas situações extremas em que somente se dispunha das informações do RREO de liquidações do exercício em investimento e pagamento total de RAPsNPs, foi necessário fazer uso de procedimentos para encontrar aproximações das liquidações efetivas, aplicando-se: i) a participação das inscrições em RAPsNPs em investimentos no ano anterior sobre o total inscrito para aproximar os pagamentos de RAPsNPs em investimentos; e ii) a participação dos investimentos empenhados em aplicações diretas sobre o total dos investimentos da EOE para aproximar os montantes referentes às aplicações diretas (exclusivamente nos estados, já que esta informação é pouco relevante nos municípios). O conjunto preciso de hipóteses adotado em cada caso foi escolhido apenas após uma análise criteriosa dos dados primários disponíveis para 
cada um dos estados e municípios individualmente. Procedimentos semelhantes foram utilizados para formar séries bimestrais das liquidações do exercício de investimento nos demais 11 estados e também de uma aleatória de 300 municípios com informações disponíveis.

3. Consolidação das séries agregadas: i) mensais da FBCF para as amostras de estados e municípios que enviaram informações mensais (15 estados, DF e 30 municípios); ii) bimestrais das liquidações do exercício em investimento e anuais da FBCF dos estados não cobertos pela amostra (11 estados); e iii) bimestrais das liquidações do exercício em investimentos dos municípios com informações disponíveis na amostra aleatória.

4. Desagregação temporal em duas etapas

a) Para formar a série mensal da FBCF dos estados não cobertos pela amostra por modelos de espaço de estado. A primeira etapa utilizou as séries anuais de FBCF e o indicador bimestral de liquidações do exercício como covariável. A nova série bimestral foi, então, desagregada em mensal a partir da série mensal da FBCF dos estados da amostra.

b) Para formar a série mensal dos investimentos dos municípios. A primeira etapa utiliza a metodologia de Orair et al. (2011), realizandose: i) a complementação da base anual Finbra por imputação das informações ausentes a partir dos indicadores de grupos homogêneos de municípios em termos de nível de renda, tamanho e localização; e ii) sua desagregação temporal a partir dos indicadores bimestrais de liquidações do exercício das informações de uma amostra aleatória de 326 municípios (divididos por grupos homogêneos). $\mathrm{Na}$ segunda etapa a série bimestral dos investimentos municipais é desagregada em frequência mensal por modelo de espaço de estado, com a série mensal da FBCF da amostra de municípios como covariável. Realiza-se, adicionalmente, um ajuste na série agregada mensal para retirar o viés que superestima o investimento público dos municípios da amostra.

5. Etapa Final Consolidação das Séries mensais da FBCF dos governos Estadual e Municipal 
Apêndice B Lista das amostras dos Estados, DF e municípios de grande porte que enviaram informações mensais de boa qualidade

Estados e DF Bahia, Ceará, Espírito Santo, Goiás, Maranhão, Mato Grosso, Mato Grosso do Sul, Pará, Pernambuco, Rio de Janeiro, Rondônia, Rio Grande do Sul, Santa Catarina, São Paulo e Tocantins.

Municípios de grande porte Rio de Janeiro-RJ, Salvador-BA, Florianópolis-SC, Belo Horizonte-MG, São Paulo-SP, Ananindeua-PA, Arapiraca-AL, AtibaiaSP, Blumenau-SC, Balneário Camboriu-SC, Boa Vista-RR, Campo BomRS, Corumbá-MS, Contagem-MG, Curitiba-PR, Cuiabá-MT, Itabira-MG, Juiz de Fora-MG, Lavras-MG, Maracanaú-CE, Porto Velho-RO, Porto AlegreRS, Recife-PE, Santa Maria-RS, São Sebastião-SP, São José dos PinhaisPR, São José do Rio Preto-SP, Serra-ES e Três Lagoas-MS 
Apêndice C Estimativas mensais da FBCF do GF, GE e GM.

Tabela C.1: Estimativas Mensais da FBCF do GF, GE e GM.

\begin{tabular}{rrrr}
\hline Mes/Ano & \multicolumn{1}{c}{ GF } & \multicolumn{1}{c}{ GE } & \multicolumn{1}{c}{ GM } \\
\hline Jan/2002 & 251,91 & 341,56 & 596,00 \\
$\mathrm{Fev} / 2002$ & 240,81 & 668,80 & 752,91 \\
$\mathrm{Mar} / 2002$ & 547,73 & 1030,70 & 888,33 \\
$\mathrm{Abr} / 2002$ & 369,28 & 846,66 & 805,95 \\
$\mathrm{Mai} / 2002$ & 388,89 & 878,49 & 1049,75 \\
$\mathrm{Jun} / 2002$ & 215,21 & 712,08 & 1143,53 \\
$\mathrm{Jul} / 2002$ & 322,40 & 1070,70 & 1120,96 \\
$\mathrm{Ago} / 2002$ & 403,52 & 1104,25 & 1090,93 \\
$\mathrm{Set} / 2002$ & 497,47 & 1049,06 & 1336,34 \\
$\mathrm{Out} / 2002$ & 525,24 & 1118,44 & 1332,54 \\
$\mathrm{Nov} / 2002$ & 488,62 & 996,65 & 1951,39 \\
$\mathrm{Dez} / 2002$ & 2439,83 & 2175,00 & 1909,80 \\
$\mathrm{Jan} / 2003$ & 165,19 & 299,69 & 939,76 \\
$\mathrm{Fev} / 2003$ & 310,47 & 559,73 & 708,24 \\
$\mathrm{Mar} / 2003$ & 105,98 & 635,23 & 857,91 \\
$\mathrm{Abr} / 2003$ & 103,78 & 523,34 & 775,35 \\
$\mathrm{Mai} / 2003$ & 124,92 & 630,64 & 931,24 \\
$\mathrm{Jun} / 2003$ & 170,90 & 697,83 & 1072,64 \\
$\mathrm{Jul} / 2003$ & 124,77 & 710,34 & 1014,64 \\
$\mathrm{Agg} / 2003$ & 151,67 & 726,20 & 1087,49 \\
$\mathrm{Set} / 2003$ & 182,45 & 857,30 & 1094,77 \\
$\mathrm{Out} / 2003$ & 220,40 & 795,51 & 1149,45 \\
$\mathrm{Nov} / 2003$ & 216,48 & 958,96 & 1591,96 \\
$\mathrm{Dez} / 2003$ & 1480,74 & 2055,58 & 1586,63 \\
$\mathrm{Jan} / 2004$ & 43,48 & 358,51 & 1222,52 \\
$\mathrm{Fev} / 2004$ & 138,92 & 404,35 & 799,13 \\
$\mathrm{Mar} / 2004$ & 192,62 & 806,08 & 996,80 \\
$\mathrm{Abr} / 2004$ & 168,24 & 658,86 & 1127,82 \\
$\mathrm{Mai} / 2004$ & 194,35 & 845,83 & 1361,78 \\
$\mathrm{Jun} / 2004$ & 233,79 & 875,76 & 1313,35 \\
$\mathrm{Jul} / 2004$ & 289,92 & 968,62 & 1283,59 \\
$\mathrm{Ago} / 2004$ & 454,79 & 978,39 & 1244,39 \\
$\mathrm{Set} / 2004$ & 341,56 & 1076,59 & 1301,48 \\
$\mathrm{Out} / 2004$ & 390,69 & 1041,53 & 1485,89 \\
$\mathrm{Nov} / 2004$ & 522,95 & 1239,57 & 1746,84 \\
$\mathrm{Dez} / 2004$ & 1224,78 & 2554,81 & 1822,65 \\
\hline $\mathrm{continua} \ldots$ & & & \\
& & &
\end{tabular}


Tabela C.1: Estimativas Mensais da FBCF do GF, GE e GM. (continuação)

\begin{tabular}{rrrr}
\hline Mes/Ano & \multicolumn{1}{c}{ GF } & \multicolumn{1}{c}{ GE } & \multicolumn{1}{c}{ GM } \\
\hline Jan/2005 & 297,28 & 482,03 & 662,35 \\
$\mathrm{Fev} / 2005$ & 310,12 & 665,22 & 342,40 \\
$\mathrm{Mar} / 2005$ & 374,37 & 815,96 & 698,84 \\
$\mathrm{Abr} / 2005$ & 289,53 & 931,96 & 720,87 \\
$\mathrm{Mai} / 2005$ & 449,86 & 991,61 & 1006,75 \\
$\mathrm{Jun} / 2005$ & 455,51 & 1019,81 & 1117,84 \\
$\mathrm{Jul} / 2005$ & 509,03 & 1055,00 & 1040,01 \\
$\mathrm{Ago} / 2005$ & 612,01 & 1260,19 & 1005,70 \\
$\mathrm{Set} / 2005$ & 455,19 & 1242,58 & 1095,02 \\
$\mathrm{Out} / 2005$ & 696,82 & 1267,39 & 1104,39 \\
$\mathrm{Nov} / 2005$ & 688,65 & 1453,60 & 2021,05 \\
$\mathrm{Dez} / 2005$ & 2059,22 & 3535,23 & 2069,53 \\
$\mathrm{Jan} / 2006$ & 426,12 & 398,42 & 934,94 \\
$\mathrm{Fev} / 2006$ & 485,32 & 730,20 & 748,64 \\
$\mathrm{Mar} / 2006$ & 562,95 & 1563,34 & 1243,30 \\
$\mathrm{Abr} / 2006$ & 427,22 & 1032,09 & 1382,21 \\
$\mathrm{Mai} / 2006$ & 580,04 & 1483,27 & 1480,22 \\
$\mathrm{Jun} / 2006$ & 749,28 & 1468,60 & 1641,76 \\
$\mathrm{Jul} / 2006$ & 622,96 & 1583,58 & 1646,59 \\
$\mathrm{Ago} / 2006$ & 780,17 & 1753,57 & 1580,91 \\
$\mathrm{Set} / 2006$ & 699,06 & 1626,85 & 1885,90 \\
$\mathrm{Out} / 2006$ & 848,04 & 1683,58 & 1838,29 \\
$\mathrm{Nov} / 2006$ & 1021,22 & 1758,14 & 2693,69 \\
$\mathrm{Dez} / 2006$ & 2013,49 & 3144,39 & 2789,37 \\
$\mathrm{Jan} / 2007$ & 562,02 & 308,32 & 1116,89 \\
$\mathrm{Fev} / 2007$ & 730,93 & 629,80 & 747,90 \\
$\mathrm{Mar} / 2007$ & 768,64 & 770,21 & 1472,04 \\
$\mathrm{Abr} / 2007$ & 698,47 & 683,31 & 1567,39 \\
$\mathrm{Mai} / 2007$ & 868,69 & 915,25 & 1710,21 \\
$\mathrm{Jun} / 2007$ & 807,50 & 939,87 & 1846,44 \\
$\mathrm{Jul} / 2007$ & 911,64 & 968,32 & 2000,85 \\
$\mathrm{Ago} / 2007$ & 970,40 & 1122,03 & 2097,84 \\
$\mathrm{Set} / 2007$ & 814,79 & 1109,91 & 1868,61 \\
$\mathrm{Out} / 2007$ & 820,40 & 1270,29 & 1680,77 \\
$\mathrm{Nov} / 2007$ & 1175,56 & 1660,79 & 2901,84 \\
$\mathrm{Dez} / 2007$ & 2329,54 & 3759,52 & 2963,44 \\
\hline $\mathrm{continua} .$. & & & \\
& & &
\end{tabular}


Tabela C.1: Estimativas Mensais da FBCF do GF, GE e GM. (continuação)

\begin{tabular}{|c|c|c|c|}
\hline Mes/Ano & GF & GE & GM \\
\hline Jan/2008 & 652,08 & 476,89 & 1384,45 \\
\hline $\mathrm{Fev} / 2008$ & 697,34 & 685,11 & 1082,88 \\
\hline Mar/2008 & 878,72 & 1119,51 & 1875,74 \\
\hline $\mathrm{Abr} / 2008$ & 922,78 & 1072,82 & 1901,78 \\
\hline Mai/2008 & 781,81 & 1377,44 & 2416,47 \\
\hline Jun/2008 & 1020,19 & 1689,63 & 2329,42 \\
\hline $\mathrm{Jul} / 2008$ & 909,21 & 1769,62 & 3008,47 \\
\hline Ago/2008 & 1107,27 & 1956,98 & 3246,20 \\
\hline Set/2008 & 1284,51 & 2078,03 & 3352,44 \\
\hline Out/2008 & 1218,99 & 1998,62 & 3495,43 \\
\hline Nov/2008 & 1509,87 & 2531,46 & 4168,92 \\
\hline Dez/2008 & 2690,14 & 5630,35 & 3841,04 \\
\hline Jan/2009 & 695,04 & 911,78 & 1334,45 \\
\hline $\mathrm{Fev} / 2009$ & 817,16 & 890,52 & 664,20 \\
\hline Mar/2009 & 1269,40 & 1814,05 & 1730,95 \\
\hline $\mathrm{Abr} / 2009$ & 1224,04 & 1678,91 & 1863,67 \\
\hline Mai/2009 & 1494,68 & 2036,65 & 2027,44 \\
\hline Jun/2009 & 1426,38 & 1925,74 & 2089,05 \\
\hline $\mathrm{Jul} / 2009$ & 1610,06 & 2364,04 & 2462,89 \\
\hline $\mathrm{Ago} / 2009$ & 1397,47 & 2488,34 & 2575,76 \\
\hline Set/2009 & 1628,28 & 2949,16 & 2231,88 \\
\hline Out/2009 & 1889,07 & 2553,50 & 2119,12 \\
\hline Nov/2009 & 1883,33 & 3484,29 & 3128,42 \\
\hline Dez/2009 & 4537,75 & 7454,03 & 3042,50 \\
\hline $\mathrm{Jan} / 2010$ & 1097,71 & 647,20 & 1530,42 \\
\hline $\mathrm{Fev} / 2010$ & 1689,26 & 2054,28 & 1117,68 \\
\hline Mar/2010 & 2648,42 & 2784,79 & 2260,82 \\
\hline $\mathrm{Abr} / 2010$ & 1861,63 & 3140,97 & 2299,84 \\
\hline $\mathrm{Mai} / 2010$ & 2429,50 & 2980,56 & 2596,08 \\
\hline Jun/2010 & 2421,47 & 3496,32 & 2513,16 \\
\hline $\mathrm{Jul} / 2010$ & 3008,46 & 3322,49 & 3388,41 \\
\hline Ago/2010 & 2234,84 & 3894,98 & 3499,95 \\
\hline Set/2010 & 2148,51 & 3722,27 & 3214,97 \\
\hline Out/2010 & 2045,69 & 3513,63 & 3042,38 \\
\hline Nov/2010 & 3213,72 & 2798,63 & 4158,17 \\
\hline Dez/2010 & 5909,21 & 7700,63 & 4499,07 \\
\hline
\end{tabular}

Fonte: Elaboração própria 